\title{
Validation of the Snow Submodel of the Biosphere-Atmosphere Transfer Scheme with Russian Snow Cover and Meteorological Observational Data
}

\author{
ZONG-LIANG YANG AND RoBert E. Dickinson \\ Institute of Atmospheric Physics, The University of Arizona, Tucson, Arizona \\ Alan Robock And K. Ya. VinNikov \\ Department of Meteorology, University of Maryland at College Park, College Park, Maryland
}

(Manuscript received 9 December 1994, in final form 25 January 1996)

ABSTRACT

\begin{abstract}
Snow cover is one of the most important variables affecting agriculture, hydrology, and climate, but detailed measurements are not widely available. Therefore, the effectiveness and validity of snow schemes in general circulation models have been difficult to assess. Using long-term snow cover data from the former Soviet Union, this paper focuses on the validation of the snow submodel in the Biosphere-Atmosphere Transfer Scheme (BATS) using 6 years of data (1978-83) at six stations. Fundamental uncertainties in the datasets limit the accuracy of our assessment of the model's performance.

In the absence of a wind correction for the gauge-measured precipitation and with the standard rain-snow transition criterion $\left(2.2^{\circ} \mathrm{C}\right)$, the model gives reasonable simulations of snow water equivalent and surface temperature for all of the six stations and the six winters examined. In particular, the time of accumulation and the end of ablation and the alteration due to aging are well captured. With some simple modifications of the code, the model can also reproduce snow depth, snow cover fraction, and surface albedo. In view of the scheme's simplicity and efficiency, these results are encouraging.

However, if a wind correction is applied to the gauge-measured precipitation, the model shows increased rootmean-square errors in snow water equivalent for all six stations except Tulun. Perhaps, the better agreement without wind correction means that the snow has blown beyond the area of snow measurement, as might be accounted for only by a detailed regional snow-wind distribution model.

This study underlines four aspects that warrant special attention: (i) estimation of the downward longwave radiation, (ii) separation of the aging processes for snowpack density and snow surface albedo, (iii) parameterization of snow cover fraction, and (iv) choice of critical temperature for rain-snow transition.
\end{abstract}

\section{Introduction}

Over the past decade, there has been an increasing interest in the construction and refinement of land-surface models (LSMs) for use in general circulation models (GCMs). As a result, there are a large number of advanced LSMs [e.g., the Biosphere-Atmosphere Transfer Scheme (BATS), Dickinson et al. 1986, 1993; the Simple Biosphere $(\mathrm{SiB})$ model by Sellers et al. 1986]. These LSMs are, in general, evaluated or calibrated in stand-alone mode prior to their implementation into GCMs (e.g., Wilson et al. 1987; Sellers and Dorman 1987; Sellers et al. 1989). The variables subject to validation are net radiation, evapotranspiration, and sensible heat fluxes because they are the elements required for coupling with the host GCMs. It has been demonstrated in numerous simulations and observational stud-

Corresponding author address: Dr. Zong-Liang Yang, Institute of Atmospheric Physics, The University of Arizona, Tucson, AZ 85721. E-mail: zly@stratus.atmo.arizona.edu ies that snow cover plays an important role in modifying regional and possibly remote climate through changes in the surface energy balance (e.g., Yeh et al. 1983; Namias 1985; Walsh et al. 1985; Barnett et al. 1989) and in affecting the hydrologic cycle via snowmelt (e.g., Aguado 1985). However, snow cover validation has not been done until now, except for Robock et al. (1995) and Douville et al. (1995a). It is, therefore, important to test these models in cold climates and to look at the snow cover simulations.

The existing numerical models of snow display a wide range of complexities. The complex treatments of Anderson (1976) and Jordan (1991), primarily oriented to the internal processes of snow, are not suitable for use in GCMs because of computational limitations. More recently, Loth et al. (1993) and Lynch-Stieglitz (1994) have independently developed multilayer snow models for global climate simulations. Their models, with relatively accurate model physics, can simulate the profiles of snow density, temperature, and water equivalent within the snowpack. However, they have not addressed 
TABLE 1. List of locations of the six stations.

\begin{tabular}{ll}
\hline \hline Station name & Location \\
\hline Yershov & $\left(51.4^{\circ} \mathrm{N}, 48.3^{\circ} \mathrm{E}\right)$ \\
Uralsk & $\left(51.3^{\circ} \mathrm{N}, 51.4^{\circ} \mathrm{E}\right)$ \\
Ogurtsovo & $\left(54.9^{\circ} \mathrm{N}, 83.0^{\circ} \mathrm{E}\right)$ \\
Kostroma & $\left(57.8^{\circ} \mathrm{N}, 41.0^{\circ} \mathrm{E}\right)$ \\
Khabarovsk & $\left(48.5^{\circ} \mathrm{N}, 135.2^{\circ} \mathrm{E}\right)$ \\
Tulun & $\left(54.6^{\circ} \mathrm{N}, 100.6^{\circ} \mathrm{E}\right)$ \\
\hline
\end{tabular}

the further details as to how snowpack is linked with vegetation and soil for use in GCMs.

The snow submodel in BATS (Dickinson et al. 1993) assumes the snow cover as a one-layer system with a time-dependent snow depth, snow density, and snow albedo for 15 types of vegetation. At every time step, the snow aging and the fraction of the grid square covered by snow are calculated, from which the thermal conductivity and volumetric specific heat of snow and the composite soil/snow layer are derived. The composite soil/snow temperature is computed using the force-restore method (Dickinson 1988). This snow submodel, in terms of snow physics, is simpler than those by Loth et al. (1993) and Lynch-Stieglitz (1994), and computationally more efficient. It is not understood to what degree of complexity snow physics should be incorporated for global simulations of climate nor with what degree of accuracy some snow physics (e.g., water vapor diffusion and liquid water movement) can be determined. Therefore, it is appropriate to evaluate the current snow submodel in BATS against the observed data before attempting to incorporate modifications.

In this paper, we test the snow cover simulations with BATS using ground-truth snow measurements. The model's ability to simulate the snow cover at different stations is examined in detail. Section 2 of our paper describes the data, section 3 outlines the model structures, and section 4 details the methodology of validation. The results from the control runs and sensitivity experiments are discussed in section 5 and a summary of conclusions is in section 6 .

\section{Data}

The snow data used in this study are contained within the soil moisture and meteorological observations in the former Soviet Union (FSU) as described in Robock et al. (1995). Six stations for the period 1978-83 were chosen for our work based on the high quality of their measured data and their widespread geographical distribution (Table 1). Each of these stations was located on a grass-covered plot. The plots were flat pieces of land with areas $\geq 0.10$ hectare and soil types representative of the main soil type and landscape of the region. Snow data were collected along snow courses, transects of $1-2 \mathrm{~km}$ in the vicinity of these stations (Barry et al. 1994), on the 10th, 20th, and the last day of each month during the winter, and were averaged. In addition, mea- surements of snow depth were taken by permanent stakes at 5-day intervals during the winter. A comparison of these two types of data is shown in Fig. 1 and their statistics are listed in Table 2. Overall, there is remarkably close agreement between the snow depth measurements from the permanent stakes and from the snow courses, implying that the vegetation was relatively homogeneous between the plot and surrounding land or that the short vegetation was the dominant surface cover near each of these six stations. Therefore, the snow course data used here are considered a relatively reliable source of both local and regional snow cover and its water equivalent.

Meteorological forcing data (air temperature, dewpoint temperature, precipitation, wind speed, air pressure, low cloud cover fraction, and total cloud cover fraction) for the period 1978-83 were measured regularly eight times per day $(0000,0300,0600,0900,1200$, 1500,1800 , and 2100) at the same time (Moscow legal time, Greenwich time plus $3 \mathrm{~h}$ ) for all six stations. The surface temperature at the soil or snow surface was also measured eight times a day. For the measurement, a standard liquid-in-glass thermometer was placed horizontally on the surface with the upper side exposed to the sun. Since such an observation may introduce a bias during the day, we only used the night observations for validation.

The actinometric data (incoming solar radiation, net total radiation, and surface albedo) came from the regular measurements of the FSU actinometric station network. These measurements were taken six times per day $(0030,0630,0930,1230,1530$, and 1830) at the mean local solar time. The data used in this paper are identical to those that were quality controlled by Robock et al. (1995).

The accuracy of precipitation data is crucial for computing water budgets and evaluating land-surface models. This is especially true for snowfall data and their use in forcing the snow submodels. Groisman et al. (1991) have reviewed the history and biases of the instrumentally observed precipitation in the FSU. According to their study, precipitation was consistently measured and sampled during a period between 1967 and 1986. D. Yang et al. (1995) have assessed the accuracy of the standard FSU precipitation gauge, and their results indicate that wind speed is the most important factor for gauge undercatch when precipitation is classified as snow. The undercatch can be as low as $40 \%$, depending on the wind speed. Based on a regression analysis of a large amount of the dataset, Yang et al. have presented formulations to correct the daily gauge snowfall according to daily mean wind speed, for example,

$$
P_{t}=100 P / R,
$$

and

$$
R=\exp \left(4.605-0.06 W^{1.4}\right)
$$



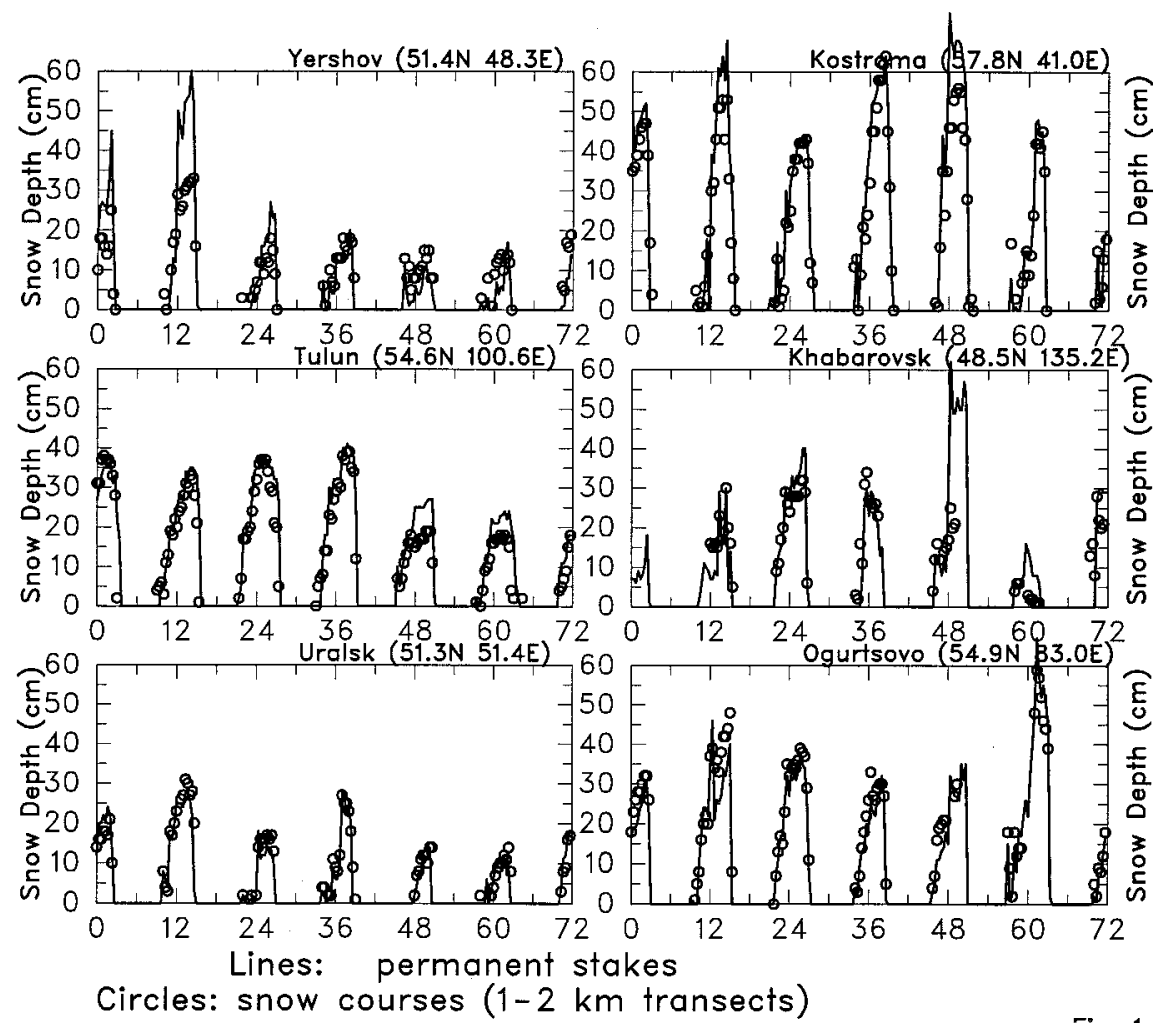

FIG. 1. Comparison of the snow depth measurements from permanent stakes (solid lines) and snow courses (circles) at 10-day intervals during the winter season. The abscissa labels indicate the beginning of the months for the period 1978-83.

where $P$ is the gauge-measured daily snowfall, $P_{t}$ is the calculated true daily snowfall estimate, $R$ is the daily gauge catch ratio of snow, and $W$ is the daily mean wind speed $\left(\mathrm{m} \mathrm{s}^{-1}\right)$ measured at the height of the gauge. However, the accuracy of any such wind correction at a specific site may be questionable and could overestimate snowfall. Therefore, we first use the observed precipitation data as they were recorded by observers at meteorological stations without theoretical wind corrections. We then compare the results with those using the

TABLE 2. Statistics for the snow depth measurements from permanent stakes and snow courses. Correlations, biases, and rms differences are computed at 10-day intervals between measurements from permanent stakes and snow courses for the entire 6-yr period. Bias is permanent stakes measurement minus snow course measurement.

\begin{tabular}{lccc}
\hline \hline Station & Correlations & $\begin{array}{c}\text { Biases } \\
(\mathrm{cm})\end{array}$ & $\begin{array}{c}\text { Rms } \\
\text { differences } \\
(\mathrm{cm})\end{array}$ \\
\hline Yershov & 0.88 & 1.66 & 9.11 \\
Uralsk & 0.90 & -0.85 & 3.80 \\
Ogurtsovo & 0.96 & -2.24 & 4.82 \\
Kostroma & 0.96 & 3.75 & 8.04 \\
Khabarovsk & 0.75 & 1.16 & 9.36 \\
Tulun & 0.89 & 3.58 & 6.31 \\
\hline
\end{tabular}

above wind correction formula. This comparison is discussed in detail in section 5 a.

\section{Description of BATS}

The content and philosophy of BATS is well documented in Dickinson (1984) and Dickinson et al. (1981, 1986, 1993). It was designed for use in the National Center for Atmospheric Research (NCAR) Community Climate Model (CCM). Many aspects have been adopted by other LSMs developed for use in various other GCMs (cf. Z.-L. Yang et al. 1995), and it has also been used in high-resolution regional climate models (e.g., Giorgi et al. 1993a; 1993b). Its snow submodel was originally described by Dickinson et al. (1981).

This section describes that submodel in some detail. Unlike the complex snow models of Anderson (1976) and Jordan (1991), which compute water and energy transfer and density changes throughout the snow column, the BATS snow submodel simulates explicitly only the snow-surface processes. There is no explicit distinction between subsurface snow versus soil temperature; that is, $T_{g 2}$ (used for a subsurface temperature) "refers, in principle, to a subsurface snow temperature after more than a few centimeters of liquid equivalent snow have accumulated. The most serious conceptual 
errors occur during time of snowmelt or rainfall on a snowpack" (Dickinson et al. 1993). Water incident on the snow surface is assumed to go directly into the soil, whereas real melt or rainwater has to percolate through the snowpack and may refreeze. The melting at the bottom of the snowpack due to heat conducted from the ground (ground melt) is also implicitly neglected unless this heat reaches the top snow surface. The submodel simulates the snow aging and its impact on surface snow density and albedo. The latent heat of fusion in the surface energy balance is considered.

\section{a. Snow mass balance}

The precipitation rate at the ground is assumed to be snowfall if the temperature at the lowest model level (equal to $2 \mathrm{~m}$ here) is less than or equal to $2.2^{\circ} \mathrm{C}$, or rainfall if this temperature is greater than $2.2^{\circ} \mathrm{C}$ (Auer 1974). Section 5e assesses the model's sensitivity to this threshold.

The snow cover at the ground is updated from

$$
\frac{\partial S}{\partial t}=P_{s}\left(1-A_{v}\right)-F_{q}-S_{m}+D_{s},
$$

where $S$ is snow mass $\left(\mathrm{kg} \mathrm{m}^{-2}\right)$ or is measured in terms of liquid water content, $P_{s}$ is snowfall rate $\left(\mathrm{kg} \mathrm{m}^{-2} \mathrm{~s}^{-1}\right)$, $D_{s}$ is the corresponding rate at which excess snow falls from the leaves $\left(\mathrm{kg} \mathrm{m}^{-2} \mathrm{~s}^{-1}\right)$, and $A_{v}$ is the fraction of grid square covered by vegetation. There is no explicit snow mass balance equation for intercepted snow on the canopy surface. The error is presumably negligible because the snow-holding capacity on the canopy surface is small (set equal to that of liquid water, that is, $0.0001 A_{v} L_{\mathrm{SAI}}$ meter of water per unit land-surface area, where $L_{\mathrm{SAI}}$ is leaf and stem area index). Snowmelt $S_{m}$ $\left(\mathrm{kg} \mathrm{m}^{-2} \mathrm{~s}^{-1}\right)$ will be discussed in section $3 \mathrm{~d}$. Rate of sublimation $F_{q}\left(\mathrm{~kg} \mathrm{~m}^{-2} \mathrm{~s}^{-1}\right)$ is parameterized as

$$
F_{q}=A_{s u} E_{g},
$$

where $A_{s u}$ is the fraction of soil covered by snow [see (11)] and $E_{g}$ the evaporation from the surface $(\mathrm{kg}$ $\left.\mathrm{m}^{-2} \mathrm{~s}^{-1}\right)$, given by

$$
E_{g}=\beta_{g} E_{p},
$$

where $E_{p}$ is potential evaporation from surface $(\mathrm{kg}$ $\mathrm{m}^{-2} \mathrm{~s}^{-1}$ ) and is parameterized using the "aerodynamic resistance" approach based on the surface layer similarity theory (Dickinson et al. 1993; Yang and Dickinson 1996). Variable $\beta_{g}$, surface wetness factor, is a function of $A_{v}$, soil moisture content and near-surface meteorological conditions, and is given by

$$
\beta_{g}=A_{s u}+\left(1-A_{s u}\right) \min \left(1, E_{0} / E_{p}\right),
$$

where $E_{0}\left(\mathrm{~kg} \mathrm{~m}^{-2} \mathrm{~s}^{-1}\right)$ is the diffusion-limited maximum evaporation from soil surface (Dickinson et al. 1993).

\section{b. Snow cover fraction}

BATS permits limited heterogeneity at the land surface such that bare soil, snow, and vegetation can all exist simultaneously in a single grid square of land. Snow can fall on either vegetation or soil surfaces. The fraction of vegetation covered by snow is parameterized as

$$
A_{s v}=d_{s} /\left(d_{s}+10 z_{0 v}\right)
$$

with

$$
d_{s}=S / \rho_{s}
$$

where

$$
\begin{aligned}
& A_{s v} \text { fraction of vegetation covered by snow } \\
& z_{0 v} \text { vegetation roughness length } \\
& d_{s} \text { average snow depth } \\
& \rho_{s} \text { snow density. }
\end{aligned}
$$

In BATS, the snow density $\rho_{s}\left(\mathrm{~kg} \mathrm{~m}^{-3}\right)$ is parameterized following the snow model and data of Anderson (1976)

$$
\rho_{s}=\rho_{\text {snew }}\left(1+3 f_{\text {age }}\right),
$$

where $\rho_{\text {snew }}=100 \mathrm{~kg} \mathrm{~m}^{-3}$ is density for new snow and $f_{\text {age }}$ is a transformed snow-age factor defined as

$$
f_{\mathrm{age}}=\tau_{s} /\left(1+\tau_{s}\right)
$$

where $\tau_{s}$ is also a nondimensional age of snow, defined as

$$
\tau_{s}^{N+1}=\left(\tau_{s}^{N}+\Delta \tau_{s}\right)\left[1-\max (0, \Delta S) / \Delta P_{s}\right],
$$

where $N$ denotes current time step, $\Delta S$ is change of snow water equivalent (in $\mathrm{mm}$ or $\mathrm{kg} \mathrm{m}^{-2}$ ) in one time step $\Delta t$, and $\Delta P_{s}=10 \mathrm{~kg} \mathrm{~m}^{-2}$ is the amount of fresh snow. Thus, $\Delta P_{s}$ indicates snowfall intensity for a given time step. A snowfall of $10 \mathrm{~mm}$ water equivalent or more in one time step is assumed to restore the surface age to that of new snow (i.e., $\tau_{s}=0$ and $f_{\text {age }}=0$ ). Here, $\Delta \tau_{s}$ is parameterized as

$$
\Delta \tau_{s}=\left(r_{1}+r_{2}+r_{3}\right) \Delta t / \tau_{0}
$$

where $\tau_{0}=1 \times 10^{6} \mathrm{~s}$. Here $r_{1}$ represents the effects of grain growth due to vapor diffusion and is expressed as

$$
r_{1}=\exp \left[5000\left(\frac{1}{273.16}-\frac{1}{T_{g 1}}\right)\right],
$$

where $T_{g 1}$ is surface temperature; $r_{2}$ represents the additional effects of grain growth near or at the freezing of meltwater,

$$
r_{2}=\left(r_{1}\right)^{10} \leq 1
$$

and $r_{3}$ represents the effect of dirt and soot,

$$
r_{3}= \begin{cases}0.01 & \text { over Antarctica } \\ 0.3 & \text { elsewhere }\end{cases}
$$



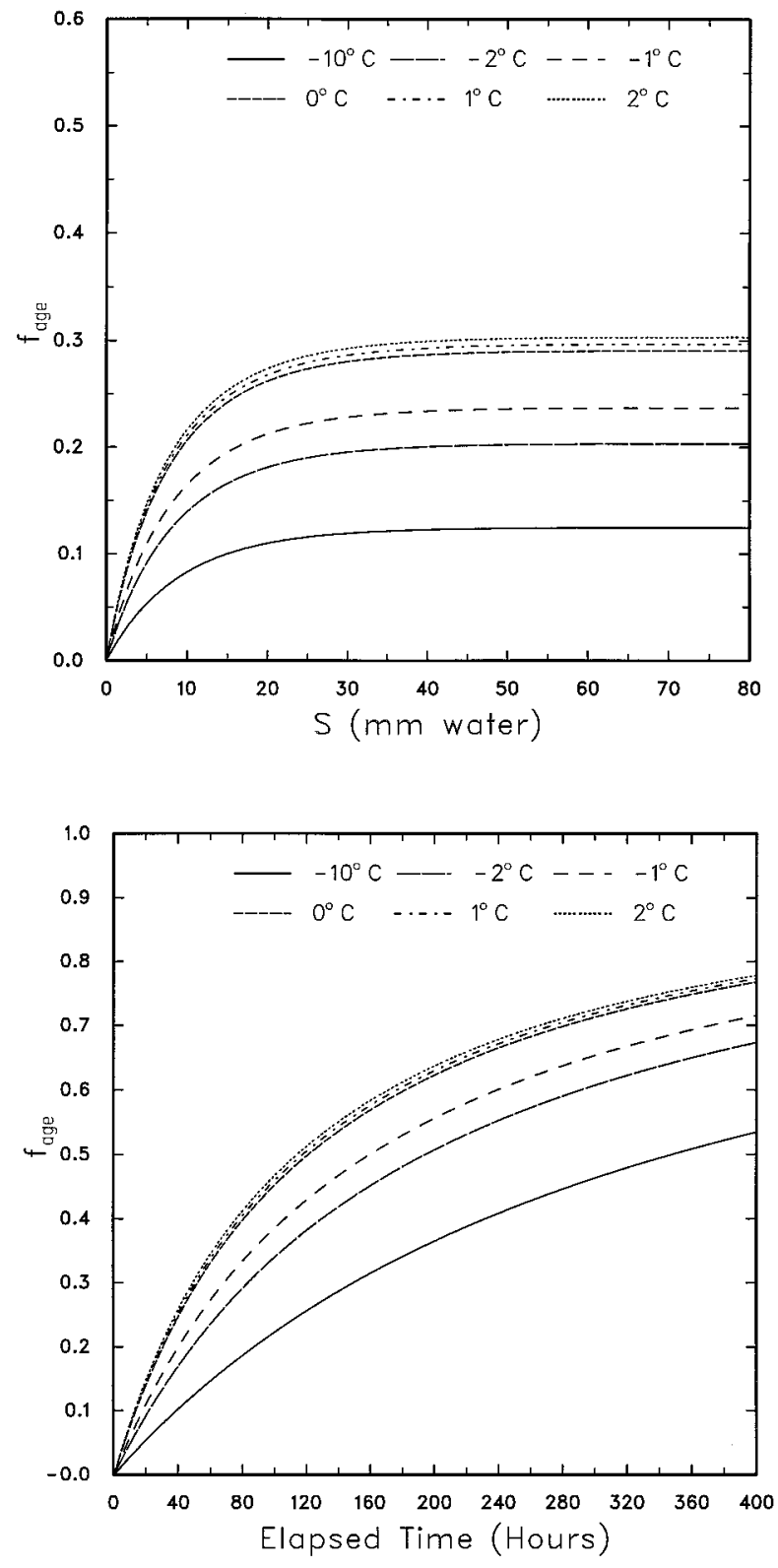

FIG. 2. (a) The factor $f_{\text {age }}$ as a function of $S$ for different snow temperatures assuming $4.8 \mathrm{~mm}$ water equivalent of snow accumulation per day and negligible snowmelt and sublimation; (b) $f_{\text {age }}$ as a function of elapsed time since a fresh snowfall.

Factor $f_{\text {age }}$ is also used to parameterize snow albedo. Figure 2a shows $f_{\text {age }}$ as a function of $S$ for different ground temperatures when there is a snowfall of $0.1 \mathrm{~mm}$ liquid water per $\Delta t(=1800 \mathrm{~s})$. The patterns are unevenly distributed for different temperatures. Here, $T_{g 1}>0^{\circ} \mathrm{C}$ is included only for illustrative purposes since the model assumes that $T_{g 1} \equiv 0^{\circ} \mathrm{C}$ during snowmelt. The terms $\tau_{s}$ and $f_{\text {age }}$ approach steady state when $S$ is beyond about $20 \mathrm{~mm}$, that is, when $\tau_{s}$ grows to values of a few tenths or so, according to (9), the addition of further snow at the prescribed rate stops further aging. Figure $2 \mathrm{~b}$ shows $f_{\text {age }}$ as a function of elapsed time since a fresh snowfall. It also shows that the snow ages quickly when there is no additional snowfall because of the influence of settling, which leads to a decrease in surface-free energy. This process is also termed as the equitemperature metamorphism or destructive metamorphism (Anderson 1976). Figure $2 \mathrm{~b}$ is essentially similar to that described in Eq. (4.29) in Anderson (1976) when similar formulations for snow melting and freezing and the dirt-soot effect are also included. At $T_{g 1} \leq-10^{\circ} \mathrm{C}$, a substantial contribution to the aging comes from the $r_{3}$ dirt factor $\left(38 \%\right.$ at $\left.T_{g 1}=-10^{\circ} \mathrm{C}\right)$.

The fraction of soil covered by snow, $A_{s u}$, is inferred according to the formula

$$
A_{s u}=d_{s} /\left(d_{s}+10 z_{0 u}\right) \text {, }
$$

where $z_{0 u}=0.01 \mathrm{~m}$ is roughness length for bare soil.

The total fraction of the grid square covered by snow is, therefore, given by

$$
A_{s}=A_{s v} A_{v 0}+A_{s u}\left(1-A_{v 0}\right),
$$

where $A_{v 0}$ is the vegetation cover fraction in the absence of snow. Here $A_{v 0}$ changes between prescribed minimum and maximum values according to a quadratic function of subsurface temperature. By definition, $A_{s}$ is always less than unity since snow is not allowed to cover completely either the vegetation [e.g., (5)] or the bare soil [e.g., (11)]. The surface albedo is expressed as

$$
\alpha=A_{s} \alpha_{s}+A_{v} \alpha_{v}+A_{u} \alpha_{u}
$$

with

$$
A_{u}=1-A_{s}-A_{v}
$$

and

$$
A_{v}=\left(1-A_{s v}\right) A_{v 0},
$$

where $A_{u}$ is the fraction of grid square covered by bare soil, $\alpha_{u}$ the soil albedo, $\alpha_{v}$ vegetation albedo, and $\alpha_{s}$ snow albedo.

The bare soil albedo $\alpha_{u}$ is dependent on soil color and soil moisture. The equations are expressed as

with

$$
\alpha_{u}=0.5\left(\alpha_{V, u}+\alpha_{I R, u}\right)
$$

$$
\begin{aligned}
\alpha_{V, u} & =\alpha_{V, u 0}+\min \left[\alpha_{V, u 0}, \Delta \alpha_{V, u}\right] \\
\alpha_{\mathrm{IR}, u} & =2 \alpha_{V, u},
\end{aligned}
$$

where

$\alpha_{V, u}$ soil albedo for $\lambda<0.7 \mu \mathrm{m}$

$\alpha_{\mathrm{IR}, u}$ soil albedo for $\lambda \geq 0.7 \mu \mathrm{m}$

$\alpha_{V, u 0}\left[=0.12-0.01\left(I_{c_{l r}}-1\right)\right]$ albedo for a saturated soil in the visible wavelength region, where $I_{c_{l r}}$ is soil color index, ranging from 1 (light) to 8 (dark)

$\Delta \alpha_{V, u} \max \left[0.01\left(11-40 w_{u}\right), 0\right]$

$w_{u}$ volumetric soil moisture content in the upper soil layer. 
TABLE 3. List of parameters prescribed for BATS.

\begin{tabular}{ll}
\hline \multicolumn{1}{c}{ Parameter } & Value \\
\hline Permanent wilting point $\left(\mathrm{m}^{3}\right.$ water $\mathrm{m}^{3}$ soil) & 0.135 \\
Soil porosity & 0.45 \\
Minimum soil suction (m) & -0.2 \\
Maximum hydraulic conductivity $\left(\mathrm{m} \mathrm{s}^{-1}\right)$ & $8.9 \times 10^{-6}$ \\
Clapp and Hornberger "B" parameter & 5.5 \\
Depth of top soil layer (m) & 0.1 \\
Rooting depth (m) & 1.0 \\
Total soil depth (m) & 10.0 \\
Fraction of total roots in top soil layer & 0.80 \\
Ratio of soil thermal conductivity to that of loam & 1.1 \\
Minimum stomatal resistance (m s $\left.{ }^{-1}\right)$ & 200 \\
Surface roughness (m) & 0.02 \\
Displacement height (m) & 0.00 \\
Interception capacity per unit projected area (mm) & 0.1 \\
Proportion of area covered by vegetation & 0.8 \\
Seasonal range of fractional vegetation cover & 0.1 \\
Maximum leaf area index & 2 \\
Minimum leaf area index & 0.5 \\
Stem area index & 4 \\
Light dependence of stomatal resistance & 0.02 \\
Leaf coefficient & 5.0 \\
Canopy visible albedo & 0.1 \\
Canopy infrared albedo & 0.3 \\
Soil color index & 2
\end{tabular}

The vegetation albedo $\alpha_{v}$ is dependent on vegetation type and zenith angle. The equations are given by

$$
\alpha_{v}=0.5\left(\alpha_{V, v}+\alpha_{\mathrm{IR}, v}\right)
$$

with

$$
\begin{aligned}
\alpha_{V, v} & =f_{Z, v} \alpha_{V, v 0} \\
\alpha_{\mathrm{IR}, v} & =f_{Z, v} \alpha_{\mathrm{IR}, v 0},
\end{aligned}
$$

where $\alpha_{V, v 0}$ and $\alpha_{\mathrm{IR}, v 0}$ are vegetation albedos in the visible and near-infrared wavelength regions, respectively. Both are prescribed in the look-up table in the code (e.g., Table 3). The solar zenith angle correction factor $f_{Z, v}$ parameterized as

$$
f_{Z, v}=0.85+1 /(1+10 \cos Z),
$$

where $Z$ is the solar zenith angle.

\section{c. Snow albedo}

BATS snow albedo uses a formulation inferred from the calculations of Wiscombe and Warren (1980) and the snow model and data of Anderson (1976):

$$
\alpha_{s}=0.5\left(\alpha_{V, s}+\alpha_{\mathrm{IR}, s}\right)
$$

with

$$
\begin{aligned}
\alpha_{V, s} & =\alpha_{V, D}+0.4 f_{Z, s}\left(1-\alpha_{V, D}\right) \\
\alpha_{\mathrm{IR}, s} & =\alpha_{\mathrm{IR}, D}+0.4 f_{Z, s}\left(1-\alpha_{\mathrm{IR}, D}\right),
\end{aligned}
$$

where $\alpha_{V, s}$ is snow albedo for $\lambda<0.7 \mu \mathrm{m}, \alpha_{\mathrm{IR}, s}$ is snow albedo for $\lambda \geq 0.7 \mu \mathrm{m}$, and the subscript $D$ denotes diffuse albedos.

Here $f_{Z, s}$ is a factor between 0 and 1 giving increase of snow visible albedo due to solar zenith angle exceeding $60^{\circ}$ and is parameterized as follows,

$$
f_{Z, s}=\frac{1}{b}\left[\frac{1+b}{1+2 b \cos Z}-1\right],
$$

where $b$ is adjustable to best available data, and is set equal to 2 in BATS. The above equation has the property that $f_{Z, s}=0$ at $\cos Z \geq 0.5$ and $f_{Z, s}=1$ at $\cos Z=0$.

The diffuse albedos are given as

$$
\begin{gathered}
\alpha_{V, D}=\alpha_{V, s 0}\left(1-0.2 f_{\text {age }}\right) \\
\alpha_{\mathrm{IR}, D}=\alpha_{\mathrm{IR}, 50}\left(1-0.5 f_{\mathrm{age}}\right),
\end{gathered}
$$

where

$$
\begin{aligned}
& \alpha_{V, s 0} 0.95 \text {, the albedo for visible radiation incident on } \\
& \text { new snow with solar zenith angle less than } 60^{\circ} \\
& \alpha_{\mathrm{IR}, s 0} 0.65 \text {, the albedo for near-infrared solar radiation } \\
& \text { incident on new snow with solar zenith angle less } \\
& \text { than } 60^{\circ} \text {. }
\end{aligned}
$$

\section{d. Snow temperature and snowmelt}

In BATS, snow and soil are lumped together for computing surface and subsurface temperatures based on an analytical approach described in Dickinson (1988), which generalized the force-restore method of Deardorff (1978). The temperature equations take the form

$$
\begin{aligned}
\frac{1+F_{\mathrm{CT} 1}}{v_{d}} \frac{\partial T_{g 1}}{\partial t}+\left(T_{g 1}-T_{g 2}\right) & =B_{\text {coef }} h_{s}, \\
\frac{1+F_{\mathrm{CT} 2}}{v_{a}} \frac{\partial T_{g 2}}{\partial t}+c_{4}\left(T_{g 2}-T_{g 3}\right) & =\frac{D_{a}}{D_{d}}\left(T_{g 1}-T_{g 2}\right),
\end{aligned}
$$

where $T_{g 1}$ is surface temperature, $T_{g 2}$ subsurface temperature, and $T_{g 3}$ deep soil temperature $(=271.0 \mathrm{~K}$ for permafrost); $c_{4}$ is a coupling constant to soil untouched by annual wave ( $=1$ for permafrost, $=0$ otherwise); and $F_{\text {Ст1 }}$ and $F_{\text {Ст2 }}$ are used to incorporate the contribution of the latent heat of freezing from the upper and rootzone soil layer, respectively, to the energy balance (Dickinson et al. 1993); $\nu_{d}=2 \pi / 86400=$ the diurnal frequency, and $\nu_{a}=\nu_{d} / 365$, the seasonal frequency. Variable $h_{s}$, the net surface heat input, is given by

$$
h_{s}=R_{n g}-F_{s}-L_{v, s} F_{q}-L_{\rho} S_{m},
$$

where $R_{n g}$ is the net radiation input at the ground surface, $F_{s}$ the atmospheric sensible heat flux from ground to atmosphere, and $F_{q}$ the atmospheric moisture flux from ground to atmosphere; $L_{v, s}$ is the latent heat of evaporation or sublimation, $L_{f}$ the latent heat of fusion; and $S_{m}$ is the rate of snowmelt.

The coefficient $B_{\text {coef }}$ is parameterized to account for the impact of the surface heating into the soil/snow medium, 


$$
B_{\text {coef }}=W_{\mathrm{TDS}} D_{d s} / K_{s}+\left(1-W_{\mathrm{TDS}}\right) D_{d b} / K_{b},(21)
$$

where $K_{s}$ and $K_{b}$ are thermal conductivities for snow and soil, respectively (Dickinson et al. 1993); $D_{d}$ and $D_{a}$ are weighted averages of penetration depths according to the depth of the snow for diurnal and seasonal heatings respectively,

$$
\begin{aligned}
& D_{d}=W_{\mathrm{TDS}} D_{d s}+\left(1-W_{\mathrm{TDS}}\right) D_{d b} \\
& D_{a}=W_{\mathrm{TAS}} D_{a s}+\left(1-W_{\mathrm{TAS}}\right) D_{a b},
\end{aligned}
$$

where the diurnal penetration depth $D_{d x}$ is

$$
D_{d x}=\left(\frac{2 K_{x}}{C_{v x} v_{d}}\right)^{1 / 2}
$$

and the seasonal penetration depth $D_{a x}$ is

$$
D_{a x}=\left(\nu_{d} / \nu_{a}\right)^{1 / 2} D_{d x},
$$

where $C_{v}$ is volumetric heat capacity, and subscript $x$ denotes snow $(s)$ or soil $(b)$. The thermal properties of snow depend on the snow density,

$$
\begin{aligned}
K_{s} & =2.9302 \times 10^{-6}\left(\rho_{s}\right)^{2} \\
C_{v s} & =2.05114 \times 10^{3} \rho_{s} .
\end{aligned}
$$

The weights for the snow contribution are

$$
\begin{aligned}
& W_{\mathrm{TDS}}=\left[1-\exp \left(\frac{-2 d_{s}}{D_{d b}}\right)\right] A_{s u} \\
& W_{\mathrm{TAS}}=\left[1-\exp \left(\frac{-2 d_{s}}{D_{a b}}\right)\right] A_{s u} .
\end{aligned}
$$

If it is snowing or if there is snow cover, we first check to see if $T_{g 1}$ is $0^{\circ} \mathrm{C}$. Snowmelt is computed from the energy required to balance $h_{s}$ and change $T_{g 1}$ to $0^{\circ} \mathrm{C}$. If positive, the inferred latent heat of melting is removed from $h_{s}$ and limited by the remaining snow cover. The meltwater is then immediately removed from the snowpack.

\section{Methodology of validation}

\section{a. Vegetation and soil type}

BATS has 18 classes of land cover, whose distribution has been obtained from the datasets of Olson et al. (1983), Matthews (1983), and Wilson and HendersonSellers (1985). Soil texture and albedo are inferred from Wilson and Henderson-Sellers (1985). Each vegetation type has 13 derived parameters that determine the morphological, physical, and physiological properties of vegetation. There are 11 soil parameters. Since the Russian data were collected from grassland sites, the vegetation type in BATS is specified as "short grass." The soil texture index 5 is used to represent the loamy soil type. The inferred hydraulic properties are based on Clapp and Hornberger's (1978) empirical relationship for soil water potential and hydraulic conductivity. Table
3 gives the values for the 24 parameters that BATS specified for short grass and "loamy soil." These are similar to the values assigned to grassland in the phase 1(a) experiments of PILPS (Project for Intercomparison of Land-Surface Parameterization Schemes; HendersonSellers et al. 1993). These same values are used for all six stations over the 6-yr period.

\section{b. Model integrations}

The model time step is $3 \mathrm{~h}$, in order to use the meteorological forcing that was available at 3-h intervals. (In a separate test, we have also interpolated the forcing data to a 30-min interval and compared the results with those from the 3-h one. Both results are essentially the same.) The soil moisture is initialized at $50 \%$ capacity, and both snow depth and snow age at zero. The downward longwave radiation is treated as described below. The model is run to reach equilibrium with the given initial soil moisture. This is achieved by looping through the first year forcing data a number of times (typically $10 \mathrm{yr}$ or less, see Z.-L. Yang et al. 1995), after which the whole 6 yr worth of data are used to drive the model. Only the results from the last $6 \mathrm{yr}$ are analyzed.

\section{c. Parameterization of downward longwave radiation}

Since the downward longwave radiation measurements were not supplied by the actinometric dataset, they had to be calculated. In our early test, a simple bulk formula of Monteith (1973) was used. Robock et al. (1995) have used a modified form of the Monteith formula to estimate $L \downarrow$ based on the Satterlund (1979) scheme, which provides improved estimates for the apparent clear-sky emissivity of atmosphere, especially when temperatures are below $0^{\circ} \mathrm{C}$. The equation may be expressed as

$$
L \downarrow=\epsilon_{a}\left[1+0.2\left(c_{L}+c_{M}\right)^{2}+0.04 c_{H}^{2}\right] \sigma T_{a}^{4},
$$

where

$\epsilon_{a}\left[=1-\exp \left(-e_{a}^{T a / 2016}\right)\right]$, apparent clear-sky emissivity of atmosphere

$e_{a}$ vapor pressure at standard level of measurement (mb)

$T_{a}$ air temperature at standard level of measurement (K)

$c_{L}$ low cloud cover fraction as provided in the data

$c_{M}\left[=0.5\left(c_{T}-c_{L}\right)\right]$, middle cloud cover fraction

$c_{H}\left[=0.5\left(c_{T}-c_{L}\right)\right]$, high cloud cover fraction

$c_{T}$ total cloud fraction as provided in the data

$\sigma\left(=5.67 \times 10^{-8} \mathrm{~W} \mathrm{~m}^{-2} \mathrm{~K}^{-4}\right)$ Stefan-Boltzmann constant. 
Strictly speaking, (25) is only applicable over some range of temperatures and other conditions present with the data used in its derivation. Any such purely empirical equation cannot be universally applied. Because Robock et al. (1995) used it for the FSU regions, we examine it first. In section 5c, we compare the simulations obtained using (25) and those from the other two methods described below.

Loth et al. (1993) estimated $L \downarrow$ based on Kimball et al. (1982). A slightly modified form of this expression is

$$
L \downarrow=\epsilon_{a} \sigma T_{\mathrm{a}}^{4}+\tau_{8}\left(c_{L}+0.75 c_{M}+0.5 c_{H}\right) f_{8} \sigma \mathrm{T}_{c}^{4},
$$

where the first term on the right-hand side represents the longwave radiation emitted by a clear sky and the second term is for the additional contribution from clouds; $\epsilon_{a}$ is the full-spectrum, clear-sky emissivity, where following Idso (1981),

$$
\epsilon_{a}=0.70+5.95 \times 10^{-7} e_{a} \exp \left(1500 / T_{a}\right),
$$

with $e_{a}$ the screen-level vapor pressure (in $\mathrm{Pa}$ ). The cloud correction depends on the temperature at the bottom of the clouds $T_{c}$ and their emissivity, the transmissivity of atmosphere $\tau_{8}$ in the water vapor window 8$14 \mu \mathrm{m}$, and the amount and type of clouds (Kimball et al. 1982). We consider the emissivity of clouds to be 1 for low clouds, 0.75 for middle clouds, and 0.50 for high clouds (Loth et al. 1993). The transmissivity of the atmosphere in the $8-14 \mu \mathrm{m}$ window, $\tau_{8}$, is

$$
\tau_{8}=1-\epsilon_{8}
$$

where $\epsilon_{8}$ is the $8-14-\mu \mathrm{m}$ emissivity of the atmosphere, which can be computed following Idso (1981),

$$
\epsilon_{8}=\epsilon_{8 z}\left(1.4-0.4 \epsilon_{8 z}\right) \text {, }
$$

where $\epsilon_{8 z}$ is the 8-14- $\mu \mathrm{m}$ sky emissivity in the zenith direction and can be determined by

$$
\epsilon_{8 z}=0.24+2.98 \times 10^{-12} e_{a}^{2} \exp \left(3000 / T_{a}\right) .
$$

Here $f_{8}$ is the fraction of blackbody radiation emitted in the $8-14-\mu \mathrm{m}$ band at temperature $T_{c}$ and can be computed from (Kimball et al. 1982)

$$
\begin{aligned}
f_{8}= & -0.6732+0.6240 \times 10^{-2} T_{c} \\
& -0.9140 \times 10^{-5} T_{c}^{2} .
\end{aligned}
$$

The cloud-base temperature is approximately calculated by

$$
T_{c}=T_{a}-1.23\left(T_{a}-T_{d}\right),
$$

where $T_{d}$ is dewpoint temperature at screen level and a temperature lapse rate of $0.01 \mathrm{~K} \mathrm{~m}^{-1}$ is assumed (Loth et al. 1993).

The final method of estimating $L \downarrow$ is to utilize the measured net radiation $R_{n}$, which was observed six times (or less) per day. It is used, whenever available, as an input to derive $L \downarrow$. When $R_{n}$ is missing at a given step, $L \downarrow$ is computed using either (25) or (26). The equation used is

$$
L \downarrow=R_{n}+\sigma\left[A_{v} T_{v}^{4}+\left(1-A_{v}\right) T_{g 1}^{4}\right]-(1-\alpha) S \downarrow,
$$

where

$$
R_{n} \text { net radiation as provided in the dataset, }
$$

$S \downarrow$ downward solar radiation as provided in the dataset,

$T_{v}$ vegetation temperature as computed by the model at the previous time step,

$T_{g 1}$ ground (soil or snow surface) temperature as computed by the model at the previous time step.

\section{d. On point data}

The data used in this paper were collected over a "point," whereas BATS, by design, is intended for use in a grid square of 50 by $50 \mathrm{~km}^{2}$ to 500 by $500 \mathrm{~km}^{2}$. However, the measured near-surface climatic variables including precipitation, solar radiation, and soil moisture were not available at these scales. Therefore, two assumptions have been made. First, the meteorological forcing data are assumed to be representative of a grid square of that size. Second, the soil and vegetation type are assumed to be representative of the same grid square. These assumptions are, in part, supported by the results shown in Fig. 1 and Table 2 as well as by the findings in Vinnikov et al. (1996).

\section{Evaluation of snow submodel in BATS}

This section describes the results from the current model [i.e., (1)-(24)] with the forcing data as given above. We first investigate the impacts of wind-corrected snowfall data on snow water equivalent (SWE) and then examine the model's sensitivity to snow-rain criterion. The results are compared for the three methods of estimating downward longwave radiation. We investigate the model's sensitivities to snow density formulation and parameterization of snow cover fraction. The performance is evaluated by comparing with the available data of snow depth, SWE, snow area fraction, surface albedo, and surface temperature.

\section{a. The impacts of wind-corrected snowfall}

In an experiment called 2.2C (see Table 4), the precipitation input is used as it was measured; in another experiment called 2.2CWIND, the measured precipitation is modified every time step only during the snow period using the formulation discussed in section 2 . Since that formulation was derived from daily snowfall and wind speed data (D. Yang et al. 1995), we first calculated daily mean wind speed from the 3-h data at the precipitation gauge height $(2 \mathrm{~m})$, which were extrapolated from measurements at a standard height of $10 \mathrm{~m}$ using a neutral logarithmic wind profile. This wind correction method may lead to some error because the 
TABLE 4. Snow water equivalent (SWE) statistics for BATS output compared to observations.*

\begin{tabular}{|c|c|c|c|c|c|c|}
\hline Experiment & Yershov & Uralsk & Ogurtsovo & Kostroma & Khabarovsk & Tulun \\
\hline \multicolumn{7}{|c|}{ Correlations of $6-y r$ run } \\
\hline $2.2 \mathrm{C}$ & 0.89 & 0.80 & 0.91 & 0.96 & 0.82 & 0.82 \\
\hline 2.2CWIND & 0.92 & 0.83 & 0.94 & 0.96 & 0.76 & 0.82 \\
\hline $0.0 \mathrm{CWIND}$ & 0.90 & 0.74 & 0.89 & 0.96 & 0.78 & 0.83 \\
\hline \multicolumn{7}{|c|}{ Biases of 6-yr run $(\mathrm{cm})$} \\
\hline $2.2 \mathrm{C}$ & 0.21 & -0.18 & -1.66 & 0.59 & 0.77 & -0.73 \\
\hline 2.2CWIND & 4.88 & 2.23 & 2.28 & 5.12 & 3.50 & -0.16 \\
\hline $0.0 \mathrm{CWIND}$ & 2.88 & 0.03 & 0.98 & 2.15 & 3.20 & -0.24 \\
\hline \multicolumn{7}{|c|}{ Rms errors of $6-y r$ run $(\mathrm{cm})$} \\
\hline $2.2 \mathrm{C}$ & 1.27 & 1.42 & 2.34 & 1.78 & 1.90 & 1.41 \\
\hline 2.2CWIND & 6.36 & 2.89 & 3.01 & 6.03 & 4.93 & 1.28 \\
\hline 0.0CWIND & 4.23 & 1.72 & 2.44 & 2.95 & 4.60 & 1.24 \\
\hline
\end{tabular}

* Correlations, biases, and rms errors are from SWE at 10-day intervals between model output and observations for entire 6-yr period. Bias is model output minus observations.

The experiment $2.2 \mathrm{C}$ refers to a simulation in which the snow-rain transition temperature was set to the standard value of $2.2^{\circ} \mathrm{C}$ and the snowfall rate was uncorrected for undercatch due to the wind effects. The experiment 2.2CWIND is the same as the experiment $2.2 \mathrm{C}$, but the snowfall rate was corrected for undercatch due to the wind effects. The experiment 0.0CWIND is the same as the experiment $2.2 \mathrm{CWIND}$, but the snow-rain transition temperature was set to $0.0^{\circ} \mathrm{C}$.

In all these experiments, downward longwave radiation is estimated using (28), that is, the NETR method as discussed in section 5c.

formula was derived from daily data, which has been necessary for us to use. Table 4 shows that the wind correction generally enhances the correlations between the simulations and observations, but increases the biases and rms errors significantly. The only exception is in Tulun where both the biases and rms errors are slightly smaller in 2.2CWIND than in $2.2 \mathrm{C}$.

There are four possible reasons for the larger biases and errors in 2.2CWIND: (i) As already mentioned, the wind correction may sometimes give an overestimate. (ii) A wind correction of a different form might be more applicable to the SWE data that were used to verify the model output because a stronger wind can affect both the gauge collection and the surrounding snow cover at the same time. When there is less snowfall caught by the gauge, there may be less snow remaining in the field and around the permanent stakes. (iii) The snow-rain criterion that partitions the precipitation input into rainfall and snowfall may be inappropriate. (iv) The parameterizations for snowmelt and sublimation may be inappropriate.

The remedy for (i) is beyond the scope of this paper. For (ii), a model that accounts for snow being blown outside the measurement area might be developed (see Pomeroy et al. 1993). However, such a model would require additional parameters for calibration and mass flux measurements for validation. Such data are not available for our sites, so we cannot derive such a model. The smaller biases and errors in the results from the 2.2C run (Table 4) suggest that the BATS snow submodel may have implicitly incorporated the blowing snow effects. Item (iii) is discussed in section $5 \mathrm{~b}$, while (iv) will be assessed indirectly in section 5c.

\section{b. Sensitivity to snow-rain temperature criterion}

Weather stations typically measure and report the water equivalent of precipitation without specifying wheth- er it is rain or snow (cf. Dingman 1994, 206-207). Physically based land surface models usually determine the form of precipitation from surface air temperature, as guided by available literature.

Based on about 1000 weather observations in which the surface $(2 \mathrm{~m})$ air temperature was recorded and the solid or liquid nature of the precipitation was clearly indicated, Auer (1974) calculated the frequency of rain versus snow reports at each temperature. He came up with a value of $2.5^{\circ} \mathrm{C}$ for surface air temperature at which the probabilities of rain and snow are equal. He reported that rain is virtually never recorded when the temperature is less than $0^{\circ} \mathrm{C}$ and snow is never observed when the temperature exceeds $6.1{ }^{\circ} \mathrm{C}$. Loth et al. (1993) investigated the sensitivity of their multilayer snow model to the value of the snow-rain criterion and found that the sensitivity is significant. Using a simple snow model, Motoyama (1990) found a snow-rain temperature threshold of $0^{\circ} \mathrm{C}$ for a cold region (Hokkaido) and $1^{\circ}-3^{\circ} \mathrm{C}$ for a warm region (Honshu) in Japan.

For GCMs, it is simplest to use a single temperature threshold for rain versus snow. The present BATS snow-rain criterion of $2.2^{\circ} \mathrm{C}$ was used in the model runs discussed above for each of the six stations. Since these stations are far apart geographically and are characterized by different climatology regimes than that of the data of Auer (1974), this constant of $2.2^{\circ} \mathrm{C}$ may not be appropriate. This snow-rain temperature threshold may depend on the site elevation (in mountains it may be higher) and on season (fall or spring).

As an alternative approach suggested by a reviewer, this threshold can be estimated for the FSU region, based on a joint assessment of precipitation event information from the "present weather code" and the surface air temperature data in an archive (NDP048) of the FSU 3- and/or 6-h meteorological data (Razuvaev et al. 
TABLE 5. Statistics of blowing snow events and wind speed during these events (personal communication from a reviewer).

\begin{tabular}{|c|c|c|c|c|}
\hline \multirow[b]{2}{*}{ Station } & \multirow[b]{2}{*}{$\begin{array}{c}\text { Number } \\
\text { of snow } \\
\text { flurry } \\
\text { events }\end{array}$} & \multirow[b]{2}{*}{ Period } & \multicolumn{2}{|c|}{$\begin{array}{l}\text { Wind speed } \\
\text { during the flurry }\end{array}$} \\
\hline & & & $\begin{array}{l}\text { Aver- } \\
\text { age } \\
\left(\mathrm{m} \mathrm{s}^{-1}\right)\end{array}$ & $\begin{array}{c}\text { Ob- } \\
\text { served } \\
\text { mini- } \\
\text { mum } \\
\left(\mathrm{m} \mathrm{s}^{-1}\right)\end{array}$ \\
\hline Kostroma & 2243 & $1936-85$ & 8.6 & 2 \\
\hline Khabarovsk & 2415 & $1953-84$ & 7.1 & 2 \\
\hline Uralsk & 1365 & $1936-85$ & 9.3 & 1 \\
\hline
\end{tabular}

1995). For 223 FSU stations (which include Kostroma, Khabarovsk, and Uralsk) for the past 50 years (193685 ), he finds the threshold is about $1{ }^{\circ} \mathrm{C}$ when only the number of snow events and rain events are counted. It is about $0.75^{\circ} \mathrm{C}$ if rain and mixed precipitation are added in one category (because mixed precipitation usually does not accumulate and cannot be considered as freshly fallen snow for radiation calculations). If, instead of precipitation events, precipitation amounts are added, he finds that this threshold is further lowered because rain intensity is usually higher than that for snowfall. For a surface air temperature of $2.2^{\circ} \mathrm{C}$, more than $80 \%$ of precipitation events over the FSU territory are rain events and only $11 \%$ are snow events. Among the 223 stations, he finds only a couple of mountainous stations have the higher probability of precipitation in frozen form than in liquid form for a temperature of $2.2^{\circ} \mathrm{C}$.

Decreasing the snow-rain criterion from $2.2^{\circ}$ to $0^{\circ} \mathrm{C}$ gives a considerable reduction in the biases and rms errors for the modeled SWE for all the stations except Tulun (Table 4). For three out of the six stations (Uralsk, Ogurtsovo, and Tulun), the simulations in 0.0CWIND are better than or equivalent to those in $2.2 \mathrm{C}$, while the opposite is true for the other three stations (Yershov, Kostroma, and Khabarovsk). These results suggest that the blowing snow events are more severe in Yershov, Kostroma, and Khabarovsk than in Uralsk, Ogurtsovo, and Tulun. This statement can be supported by examining the statistics of blowing snow events and wind speed during these events using the archive NDP048 of the FSU 3-h meteorological data (Razuvaev et al. 1995) (see Table 5).

All the results further presented assume the wind correction as discussed above and snow-rain transition temperature at $0^{\circ} \mathrm{C}$. All conclusions also apply to the $2.2 \mathrm{C}$ run.

\section{c. Sensitivity to downward longwave radiation}

Figures 3a-d illustrate the time series of precipitation, snowfall, snow cover depth, SWE, and snow area fraction for Uralsk (the 0.0CWIND case). The observed values are shown for snow cover depth [i.e., $d_{s}$ in (6)], SWE (or $S$ ) and snow area fraction [i.e., $A_{s}$ in (12)], and compared with simulated using the three methods of computing $L \downarrow$, namely, the Satterlund method [(25)] (hereafter SATT), the Kimball et al. method [(26)-(27)] (hereafter KIA), and the observed net radiation method [(28)] with the Kimball et al. method used when the observed net radiation was not available (hereafter NETR). The observed snow cover depth and SWE display a strong interannual variability. The observed snow cover fraction can be up to $100 \%$, lasting for almost all the period when there is snow on the ground.

Overall, the simulations (Figs. 3b-c) show a strong correspondence between the observed and the modeled values of snow depth and water equivalent. The time of accumulation and the end of ablation are accurately modeled. The interannual variability of snow cover is also captured well. Of the three methods of computing $L \downarrow$, the NETR method gives the best simulations of SWE. These results indicate a strong sensitivity of the model to the estimation of $L \downarrow$. The SWE is, in general, simulated better than the snow cover depth; the latter is overestimated over most of the snowing period (e.g., by a factor of 2 for the winter of 1978/79). The simulated snow depth shows spikes, indicating that the modeled snow density is oscillating between small and large values. This is more obvious when snowfall is heavy (e.g., in Kostroma). We suggest that this discrepancy results because the snow density as given in (6) would best be interpreted as representing that of the near-surface layer and not the whole snow column (section 5d). The simulated snow cover fraction ranges from $0 \%$ to $90 \%$, in contrast to the observed $100 \%$ over most of the snow season, and has a pattern of interannual variation similar to that for the simulated snow cover depth and SWE.

The time series of precipitation, snowfall, snow cover depth, SWE, and snow area fraction are also shown for Yershov (Fig. 4), Ogurtsovo (Fig. 5), Khabarovsk (Fig. 6), Tulun (Fig. 7), and Kostroma (Fig. 8). Overall, the model produces results for all stations similar to those for Uralsk. The snow depth is too high, the spikes in the snow depth persist in the model with all the three methods, and the snow cover fraction is consistently under-predicted. The SWE is best reproduced by the NETR method for Tulun; but for Yershov, Ogurtsovo, Khabarovsk, and Kostroma, the KIA method gives the best simulations. These results indicate that the KIA method may be more appropriate than the SATT method in estimating $L \downarrow$ for these five sites. The sensitivity to the method of estimating $L \downarrow$ is also illustrated in Fig. 9. With the SATT method, both snow depth and SWE are largely overestimated (Fig. 9a); with the KIA method, the modeled and observed snow depth and SWE show an improved correlation (Fig. 9b).

The overestimated snow depth, or the underestimated snow density, affects the estimation of snow cover fraction [e.g., (5), (11), and (12)], the surface albedo [e.g., (13)], surface wetness factor [(4)], and snow/soil temperatures [e.g., (19)-(24)], a complex chain of effects that is discussed later. 

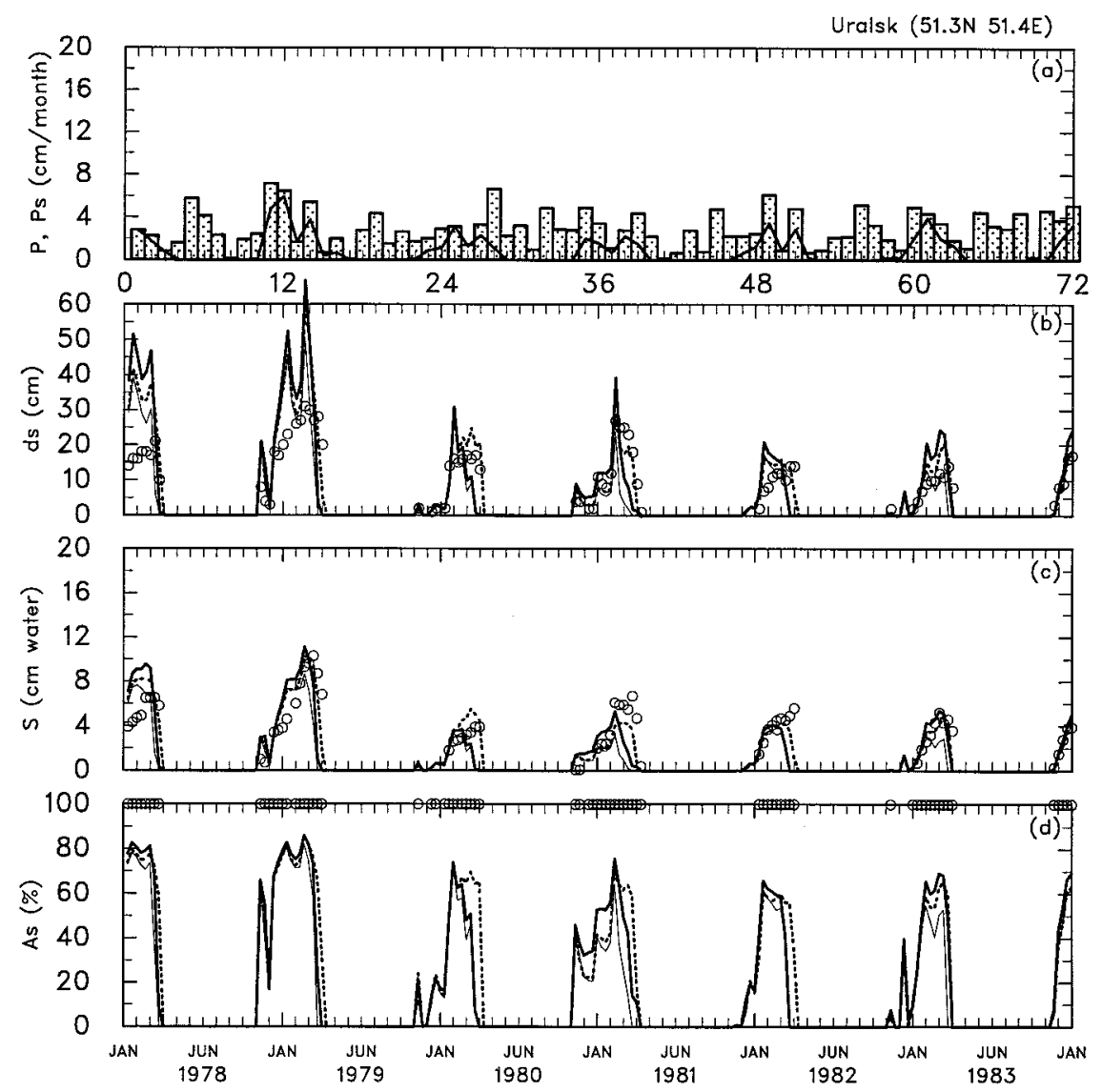

FIG. 3. Six-year time series of (a) precipitation $\left(\mathrm{cm} \mathrm{mo}^{-1}\right.$ shown by vertical bars) and snowfall ( $\mathrm{cm} \mathrm{mo}{ }^{-1}$ shown by solid lines), (b) snow cover depth $(\mathrm{cm}),(\mathrm{c})$ snow water equivalent $(\mathrm{cm})$, and (d) snow area fraction (percentage) for Uralsk. The precipitation (observed) and snowfall (estimated) are shown as monthly accumulated. The measurements (shown by circles) of snow depth, snow water equivalent, and snow cover area fraction from snow courses were made every ten days during the winter season. The simulations were obtained as the daily means on the same date. The modeled results from three methods of estimating downward longwave radiation are shown. The thick solid line is for the SATT method [(25)], the dot line for the NETR method [(28)], and the thin solid line for the KIA method [(26)-(27)].

To explore which of the above three methods [i.e., (25), (28), and (26)-(27)] for downward longwave radiation is most appropriate, we have plotted the diurnal variations of net radiation, downward longwave radiation, and ground surface temperature for a typical period of 10 days starting from 11 January 1981 (see Fig. 10a for Uralsk and Fig. 10b for Kostroma). The observed net radiation, surface temperature (nighttime only), and surface air $(2 \mathrm{~m})$ temperature are also added for comparison. In general, both observed temperatures are very close. Both the KIA and the NETR methods give similar estimates of net radiation, and both are in close agreement with the observed, whereas the SATT method underestimates values. Similar patterns can be seen in $L \downarrow$. As a result, the ground temperatures from the KIA and NETR methods are in better agreement with the observed, while the SATT method produces the largest cold bias.

The generalized force-restore method in BATS ap- pears to adequately simulate the diurnal and day-today variations of the surface temperature when snow is present on the ground. Since the surface temperature, snow age, density, snowmelt, and snow depth are related to one another as described in section 3, optimum simulations of surface temperature should, in principle, result in the best simulations of snow depth and SWE.

To further comprehend what determines the SWE and $d_{s}$ trajectories, we have plotted the accumulated precipitation, snowfall, evaporation (or sublimation), and snowmelt for a complete snow season from 1 October 1980 to 31 May 1981 for Kostroma (Fig. 11). The values from all three methods of estimating downward longwave radiation are shown. Because precipitation is prescribed and snowfall rate is determined by the input air temperature, their accumulation plots for the three methods of estimating $L \downarrow$ are identical. However, evaporation (sublimation) and snowmelt show distinct plots for the three methods. During the accumulation season (before 


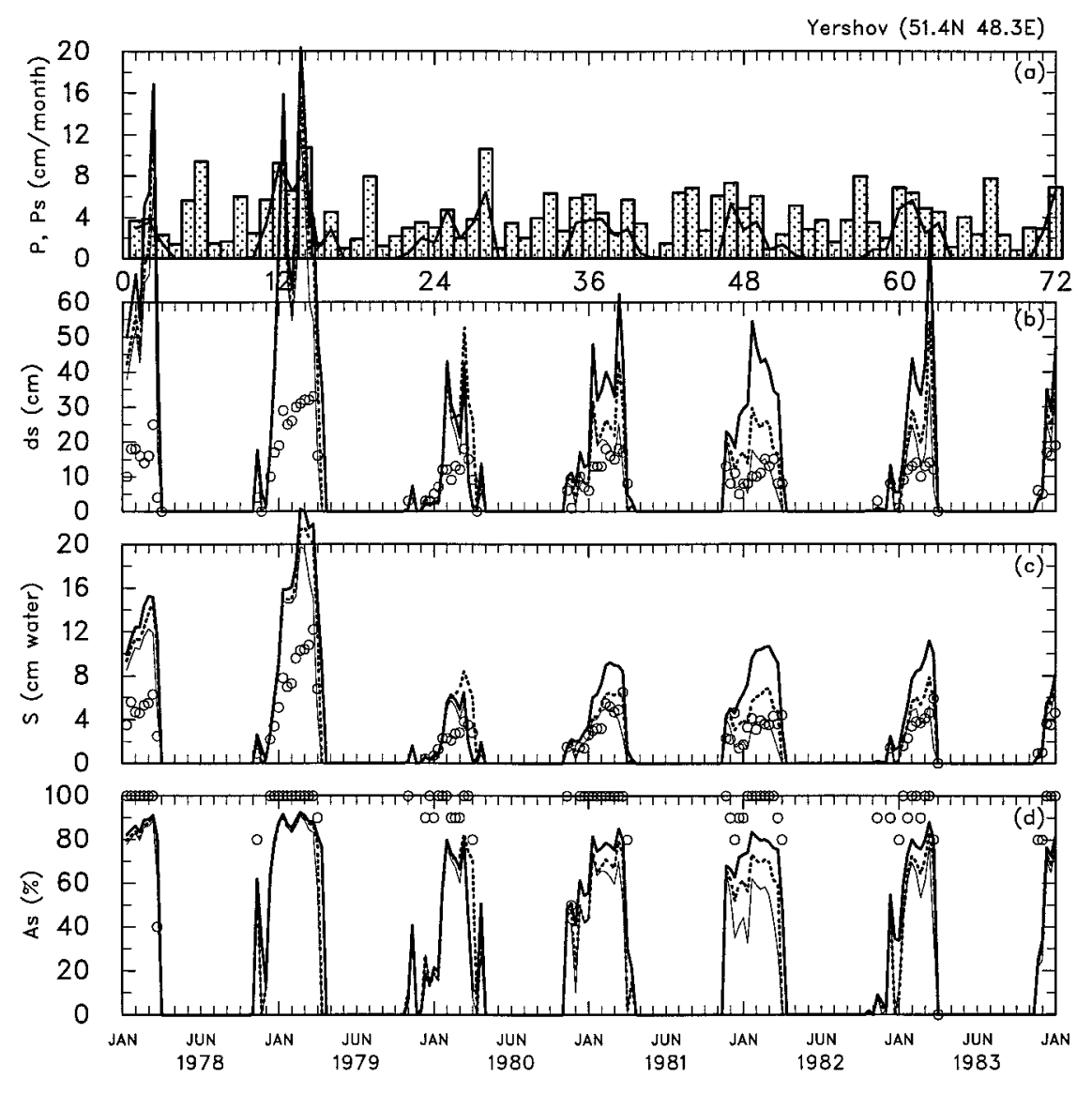

FIG. 4. As in Fig. 3 but for Yershov.

day 172), which is long, lasting about 4 months, both sublimation and snowmelt are small, which account only for about one-tenth of the input of snowfall. During the ablation season (days 172-213), which is short (just over 1 month), both snowfall and sublimation are small, while snowmelt is dominant. All these processes are plausible. (We have compared the simulations of the daytime and nighttime sublimation with the corresponding observations. Despite a large scatter in the 1:1 plot, the range of the sublimation values is well simulated by the model with the NETR method.) The overestimated SWE and $d_{s}$ with the SATT method (Fig. 9a) can be explained by the smallest snowmelt and the negative "sublimation" during the accumulation season (Fig. 11). With the KIA method, the snowmelt is the largest, and there is a positive loss of snow by sublimation (Fig. $11)$, corresponding to the realistic surface temperature (cf. Fig. 10b). As a result, the simulations of SWE and $d_{s}$ are improved (Fig. 9b).

In summary, the winter and spring snowmelt and sublimation are very sensitive to the calculation of the downward longwave radiation. The Earth Radiation Budget Experiment (ERBE) data are now commonly used to validate the top-of-the-atmosphere (TOA) out- going longwave radiation, reflected shortwave radiation, and the Surface Radiation Budget (SRB) data (Pinker et al. 1995) for the downward and reflected shortwave radiation at the surface as simulated by GCMs (Hahmann et al. 1995). However, there has been relatively little study devoted to the validation of the downward longwave radiation at the surface. In addition, the estimate of radiative fluxes and layer cloud from satellites is especially problematic at high latitudes or over snowcovered regions (e.g., Drake 1993; T. P. Charlock 1994, personal communication). GCM longwave radiation codes are physically based but their surface downward flux calculations depend on cloud bases and water vapor concentrations that may not be adequately realistic. To some extent, at least, errors in their downward longwave fluxes at the surface could lead to anomalous simulations of snow cover and possibly have far-reaching effects on large-scale climate over a large part of the year (Yeh et al. 1983).

\section{d. Sensitivity to snow density formulation}

Substantial overestimation of $d_{s}$ still persists (e.g., Fig. 9b) despite the improved estimate of downward 



FIG. 5. As in Fig. 3 but for Ogurtsovo.

longwave radiation. These overestimated values are manifested in spikes (cf. Fig. 12), suggesting that snow density is oscillating between large and small values. Since these occur when there is a heavy snowfall (Figs. 3-8), we examine an important constraint $\Delta P_{s}$ used in the snow density formulation, (9). The related parameterizations, (7)-(10), are intended to mimic the surface snow processes, especially for computing surface temperature. Therefore, the density computed this way refers to the surface snow density, and use for total snow depth may have a large error when there is a heavy snowfall. To better match the observed snow depth, the diagnostic form of the snowpack thickness is modified to

$$
d_{s}=S_{1} / \rho_{s 1}+S_{2} / \rho_{s 2},
$$

where $S_{1}=\min \left(S, 50 \mathrm{~kg} \mathrm{~m}^{-2}\right)$ and $S_{2}=\left(S-S_{1}\right)$. Equations (7)-(10) are still used for computing $\rho_{s 1}$, but (9) is modified slightly for $\rho_{s 2}$ which is considered only when $S \geq 50 \mathrm{~kg} \mathrm{~m}^{-2}$. The nondimensional snow age, $\tau_{s 2}$, used for computing $\rho_{s 2}$, is defined as

$$
\tau_{s 2}=\tau_{s i n i}+\Delta \tau_{s 2},
$$

where $\tau_{\text {sini }}$ is the value of $\tau_{s}$ when $S_{2}$ becomes greater than zero, and

$$
\Delta \tau_{s 2}=\left(r_{1}+r_{2}\right) \Delta t / \tau_{0} .
$$

These formulations require that the top $50 \mathrm{~mm}$ liquid equivalent snow and the remaining layer are subject to different aging processes; the bottom layer aging neglects the impacts of the fresh snow and soot, while the top layer aging considers all the factors, as in section $3 \mathrm{~b}$. Using these formulations, the spikes in the modeled snow depth persist but with a much smaller magnitude (not shown).

Since the standard snow density formulations (7)(10) are capable of reproducing the snow depth when the snowfall is not heavy (cf. Figs. 3-8), we retain this framework and examine how $d_{s}$ depends on the value of $\Delta P_{s}$, a scale for the snowfall in a time step that provides fresh snow. In the previous simulations, $\Delta P_{s}=$ $10 \mathrm{~mm}$ was assumed. In a new test, $\Delta P_{s}=60 \mathrm{~mm}$ is used only when computing the snow density, while the standard $10 \mathrm{~mm}$ remains unchanged in (9) for the snow albedo parameterization.

Figure 12 compares the time series of $d_{s}$ and $S$ from the model with the standard and modified snow density formulations as discussed above. In both cases, the downward longwave radiation was estimated using the KIA method. The modified constraint in the snow den- 


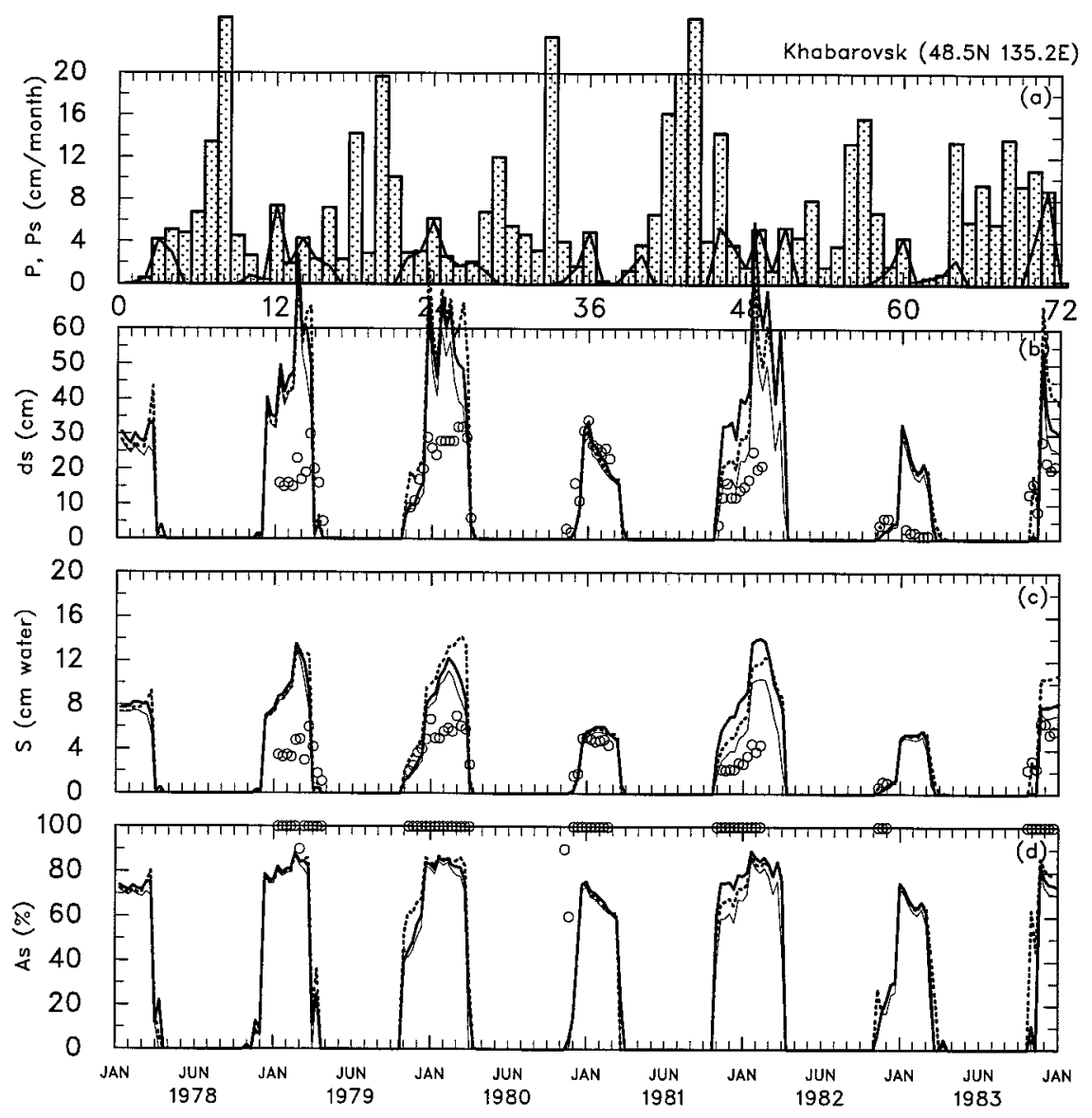

FIG. 6. As in Fig. 3 but for Khabarovsk.

sity formula eliminates the fictitious spikes and results in an excellent simulation of $d_{s}$, while there is small but favorable change in the modeled $S$ (and surface temperature, not shown) compared to that by the standard constraint. We have verified that $\Delta P_{s}$ is independent of time step, and that $\Delta P_{s}=60 \mathrm{~mm}$ also works better for finer time steps than the standard $10 \mathrm{~mm}$. For instance, the experiment with $\Delta P_{s}=60 \mathrm{~mm}$ and the interpolated 30 -min forcing produces results that are essentially identical to those from the experiment with $\Delta P_{s}=60 \mathrm{~mm}$ and the 3-h forcing.

\section{e. Sensitivity to parameterization of snow cover fraction}

The model underestimates the snow cover fraction $A_{s}$ during the snow period for all the six stations considered (cf. Figs. 3-8). The values of $A_{s}$ as given by (5) and (11) (Fig. 13) are much less sensitive to $L \downarrow$ than is $d_{s}$. Consequently, the modeled snow albedo and the terrestrial surface albedo [i.e., (13)] are also not sensitive to $L \downarrow$. The surface albedo is underestimated by as much as $0.2-0.3$ (Fig. 14) in winter. A slight disagreement in summer is mainly due to the specification of vegetation albedo, but its study is not in the scope of this work.
Baker et al. (1991) have discussed the snow depth required to mask the underlying surface based on the measurements of the daily mean surface albedo and snow depth collected over sod, alfalfa, and bare soil over the course of 19 winters at the University of Minnesota-St. Paul campus. Their results show that there are two distinct stages for the surface albedo/snow depth relationship. During the first stage, the surface albedo increases sharply as snow depth increases before it reaches a critical depth. During the second stage or once the snow depth reaches the critical depth, the surface albedo shows a markedly slow increase as snow depth increases. Comparison of the time series of snow depth and snow cover fraction in our data also suggests a similar two-stage relationship. Therefore, the functional form for snow cover fraction and snow depth is proposed to be

$$
A_{s}^{i}=\tanh \frac{d_{s}}{2.5 z_{0}^{i}},
$$

where the subscript $i$ denotes some kind of surface type, for example, bare soil or grass. Equation (32) states that $A_{s}^{i}=0$ if there is no snow, $A_{s}^{i}=76 \%$ if $d_{s}=2.5 z_{0}^{i}$, and then $A_{s}^{i}$ gradually approaches unity as $d_{s}$ increases 


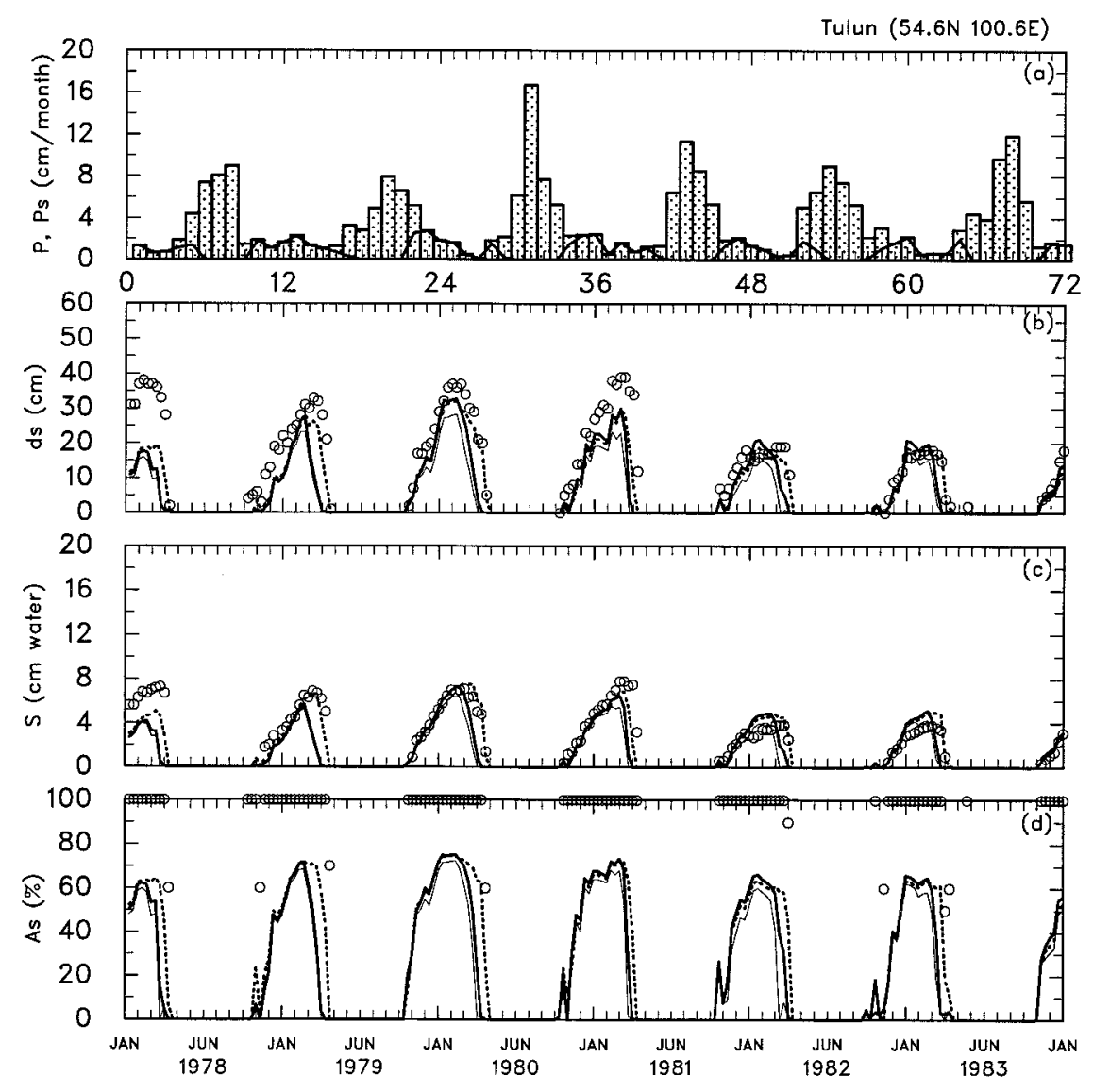

FIG. 7. As in Fig. 3 but for Tulun.

further. This expression indicates that vegetation is half covered by snow when $d_{s}=1.4 z_{0} \approx 3 \mathrm{~cm}$, about $15 \%$ of the nominal height of the vegetation. This may not be surprising for short and weak grass because its height can be lowered by the snow weight. Equation (32) can be compared to $d_{s} /\left(d_{s}+z_{0}\right)$ (Fig. 13). In the latter formula, $A_{s}$ never reaches unity even with $60 \mathrm{~cm}$ of snow, and as the coefficient in front of $z_{0}$ increases, $A_{s}$ decreases. In the case of $10 z_{0}$, the formula indicates that a snowpack of $60 \mathrm{~cm}$ can cover merely $70 \%$ of vegetation (of $20 \mathrm{~cm}$ tall).

Figure 14 compares the simulations of the snow cover fraction and the monthly (solar) energy-weighted mean albedos [cf. Eq. (1) in Barker et al. 1994] over the entire period of 6 years. With this new relationship, the simulated snow cover fraction and surface albedo show remarkably close agreement with the observed.

The new form may be most appropriate for grasses and agricultural lands, which commonly have vegetation slumping due to snow burdening. For open boreal forest, however, an exponential description of snow masking may be more appropriate as suggested by Barker et al. (1994). For the GCM grid square of $500 \mathrm{~km} \times 500 \mathrm{~km}$ with greater roughness (i.e., with the presence of widespread tall forests or mountain ranges), the exact form of snow masking is difficult to establish, but it is unlikely to reach unity since such a region is difficult to bury completely. Douville et al. (1995b) have proposed a formula for a GCM grid square with the irregular distribution of snow cover in the mountainous areas,

$$
A_{s}=d_{s} /\left(d_{s}+10 z_{0}\right) \sqrt{d_{s} /\left[d_{s}+\max \left(1 ., 0.15 \times \sigma_{z}\right)\right]},
$$

where $d_{s}$ is snow depth in meters and $\sigma_{z}$ is the standard deviation of the subgrid orography expressed in meters. However, an exact form suitable for a GCM grid square could only be established with remote sensing observations of snow cover data.

\section{Summary}

The snow scheme in BATS, as described by (1)-(24), has been tested with snow cover and meteorological data collected over the FSU. The basic aspects of the model, including snow depth, snow water equivalent, snow cover fraction, surface albedo, and surface temperature, are evaluated using the available data. The fundamental uncertainties in the datasets limit the degree to which we can test the model's performance.

Our results show that in the absence of a wind cor- 


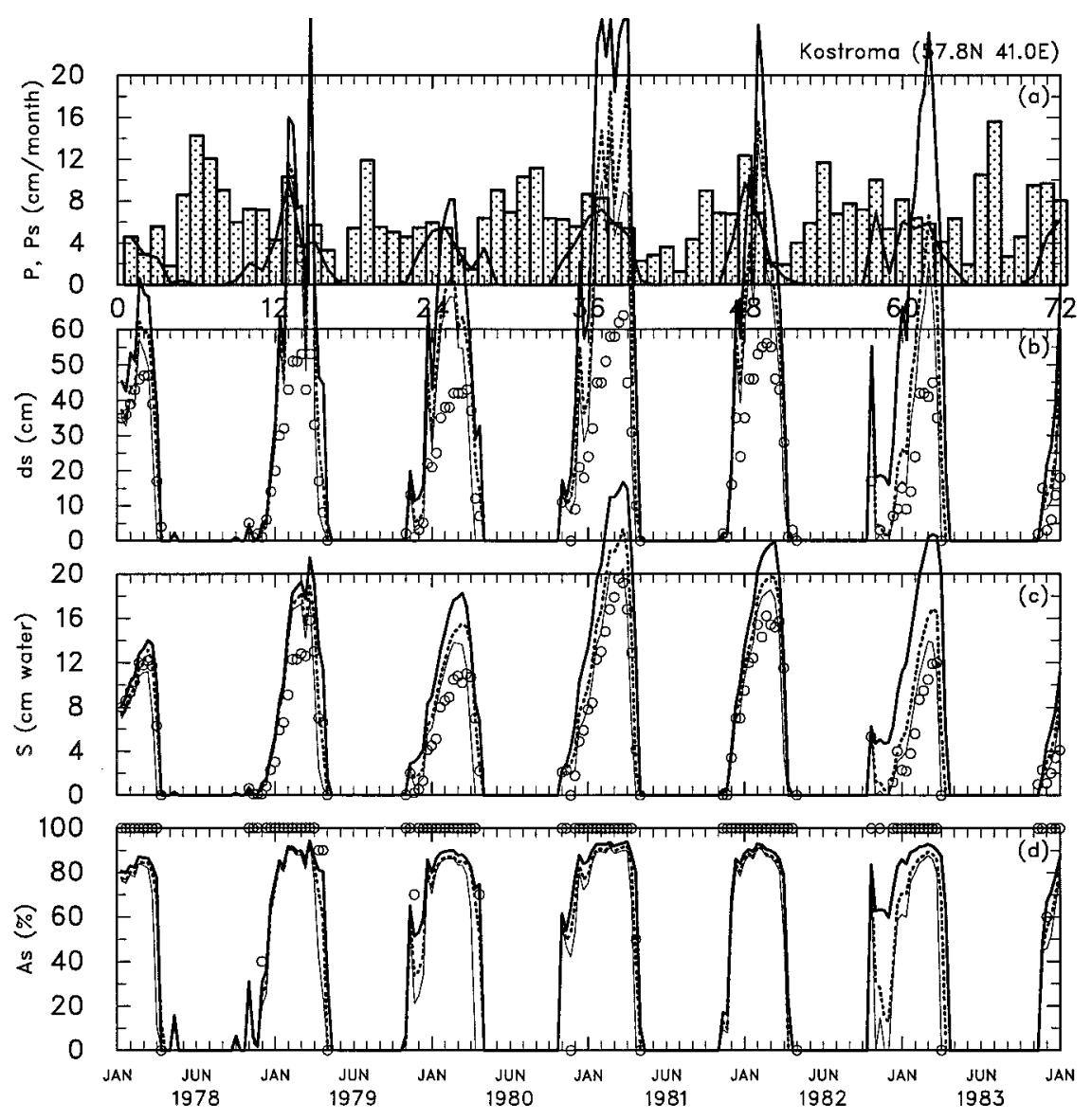

FIG. 8. As in Fig. 3 but for Kostroma.

rection for the gauge-measured precipitation and with the standard rain-snow transition criterion $\left(2.2^{\circ} \mathrm{C}\right)$, the model produces reasonable simulations of snow water equivalent and surface temperature for all of the six stations and the six winters examined. In particular, the time of accumulation, the end of ablation, and the alteration due to aging are well simulated. With some simple modifications of the code suggested by recent observations, the model can also reproduce snow depth, snow cover fraction, and surface albedo. In view of the scheme's simplicity and efficiency, these results are encouraging.

However, if the presently available wind correction is used for the gauge-measured precipitation, the model shows increased rms errors in SWE for all the six stations except Tulun. The effects of blowing snow events might be accounted for in a more advanced wind distribution model, but such a model would require additional parameters for calibration and mass flux measurements for validation. On the other hand, based on the fact that BATS, having a reduced amount of SWE as output matches better the data with a reduced amount of snowfall as an input, we might infer that the model has implicitly incorporated the blowing snow effects. In other words, with stronger wind, less precipitation may be caught by the gauge, and at the same time less snow (approximately by the same amount) may remain on the open sites. Since these two terms cancel each other, the gauge-measured precipitation may not need correction to match snow measurements in surrounding fields but only to represent a larger area including forests where the snow accumulates.

Our study underlines four aspects that warrant special attention: (i) estimation of the downward longwave radiation, (ii) separation of the aging processes for snowpack density and snow surface albedo, (iii) parameterization of snow cover fraction, and (iv) choice of critical temperature for rain-snow transition.

Downward longwave radiation is often not measured. We found that the empirical formula used to estimate it may have a large impact on the performance of the snow model. Among the three methods (i.e., SATT, NETR, and KIA) tested, the KIA method performs well in terms of SWE and surface temperature for Kostroma, while the SATT method overestimates SWE and gives a cold bias in surface temperature for Kostroma and the other stations. The NETR method (but for $L \downarrow$ estimated by KIA when the observed net radiation is missing) provided good overall performance in the simulations of snow water equivalent and surface temperature. Our 

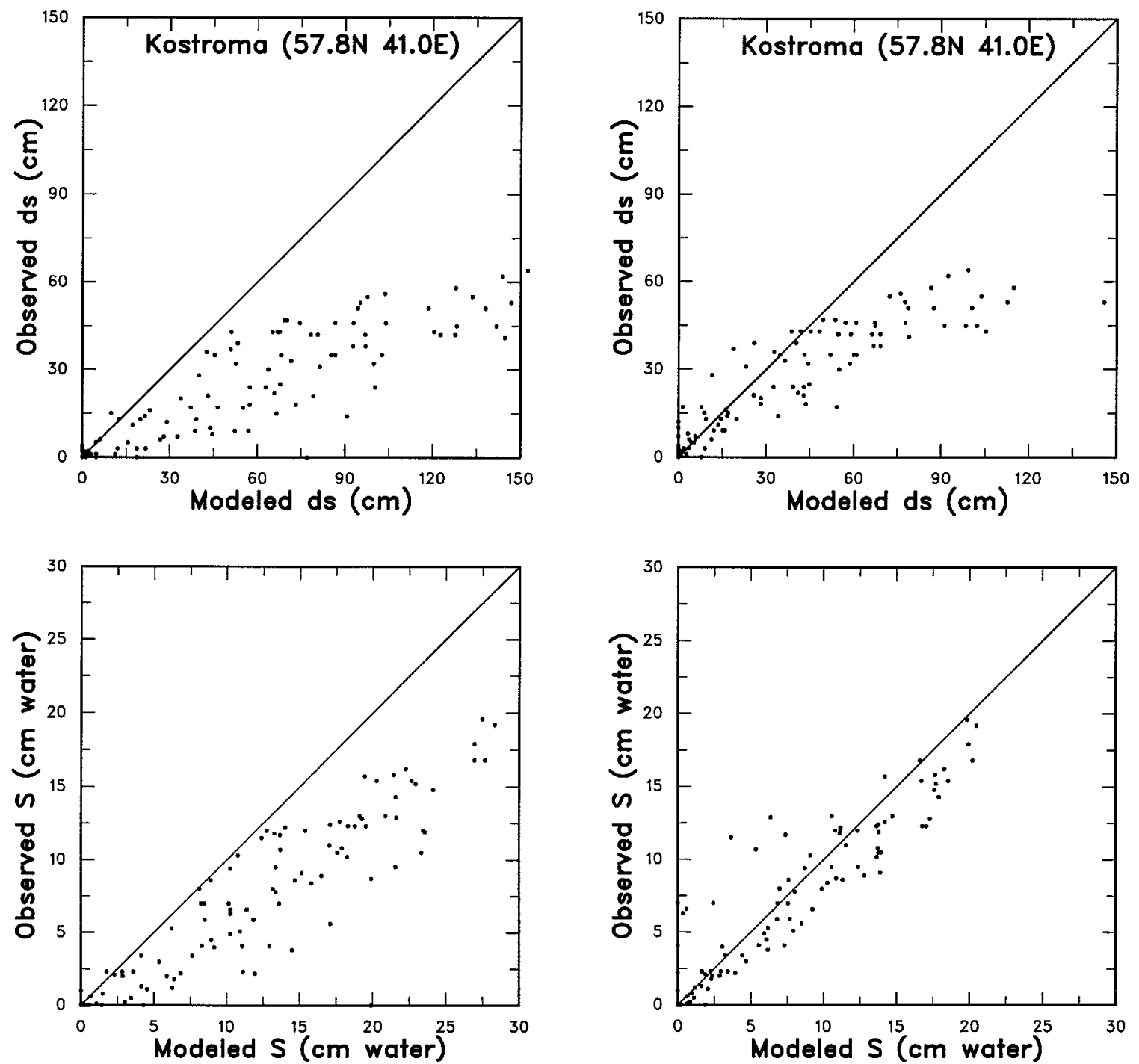

FIG. 9. One-to-one plot of modeled versus observed snow depth (top panel) and water equivalent (bottom panel) for Kostroma. (a) The SATT method [(25)]; (b) the KIA method [(26)-(27)].

study indicates that the validation of the downward longwave radiation in GCMs, which has received little attention in the recent validation studies, is an important issue that needs to be addressed.

The snow-aging processes, or the metamorphism of snow, determine the snow density and the snow surface albedo. In BATS, the aging term parameterizes the grain growth due to vapor diffusion, additional effects near or at the freezing of meltwater, and the effects of dirt and soot. The aging is reduced by the occurrence of new snow; the original parameterization assumes an identical form for both surface snow density and surface albedo. However, the constraint of $10 \mathrm{~mm}$ water equivalent snowfall used in (9) is shown to be too low for the dataset used here. The snow depth estimated using the above formulations for snow density compares well with the observed, only provided the snowfall is light.
By using a larger constraint $(60 \mathrm{~mm})$ for the snow density only, the simulations of snow depth are generally in close agreement with observations, while there are small but favorable changes in SWE and night surface temperature.

The parameterization of snow patches is important for a proper simulation of surface albedo and energy balance. The original snow cover parameterization is shown to underestimate snow cover fraction and surface albedo. An improved snow cover parameterization can correct this deficiency, but also slightly degrades the simulations of surface temperature and SWE, because the enhanced surface albedo leads to decreased net radiation, which, in turn, results in lower surface temperature and less sublimation and snowmelt, which further increases SWE and/or snow depth. Our proposed form of the snow cover fraction is derived from data 

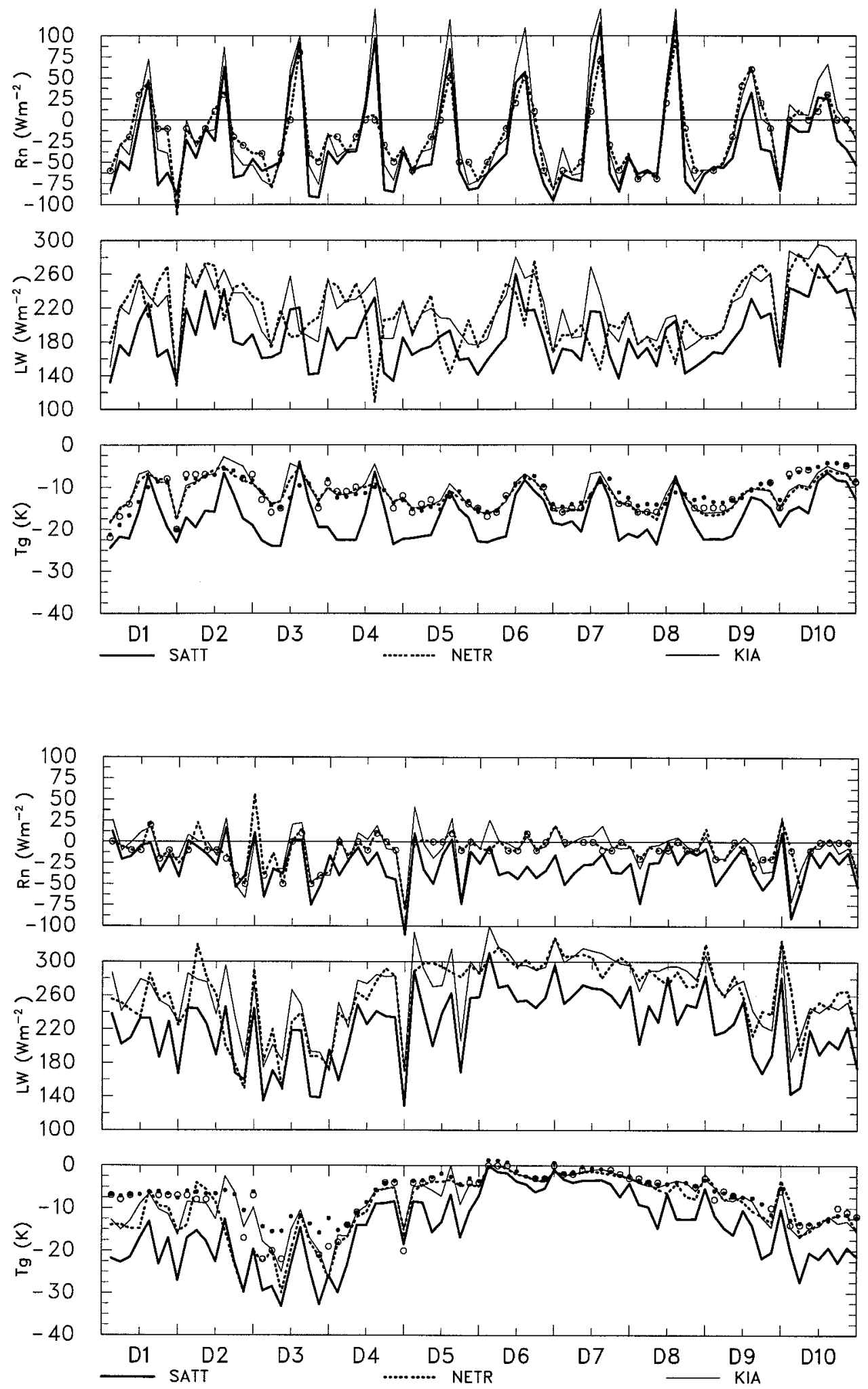

FIG. 10. Comparison of diurnal variations of net radiation (top panel), downward longwave radiation (middle panel), and surface temperature (bottom panel) during 11-20 January 1981 from three methods of estimating downward longwave radiation: (a) Uralsk and (b) Kostroma. The thick solid line is for the SATT method [(25)], the dot line for the NETR method [(28)], and the thin solid line for the KIA method [(26)-(27)]. Observed net radiation and surface temperature (nighttime only) are shown by open circles, while observed surface air $(2-m)$ temperature is shown by solid circles. 




FIG. 11. Cumulative time series of precipitation (top panel), snowfall (second panel), sublimation (third panel), and snowmelt (bottom panel) for Kostroma for a period from 1 October 1980 to 31 May 1981. The results from three methods of estimating downward longwave radiation are compared. The thick solid line is for the SATT method [(25)], the dot line for the NETR method [(28)], and the thin solid line for the KIA method [(26)-(27)].



FIG. 13. Proposed relationships between snow depth and fraction of a surface $\left(z_{0}=2 \mathrm{~cm}\right)$ covered by snow.

obtained from small-scale flat plots of low vegetation and bare soil. The exact form applicable to the largescale with orography or tall vegetation in a GCM context can be obtained only from satellite data.

The form of precipitation (i.e., snow versus rain) is not available in a typical weather station report. Physically based land-surface models usually determine the form of precipitation from surface air temperature. The available literature shows a wide range of choices for this temperature that may depend on geographical lo-
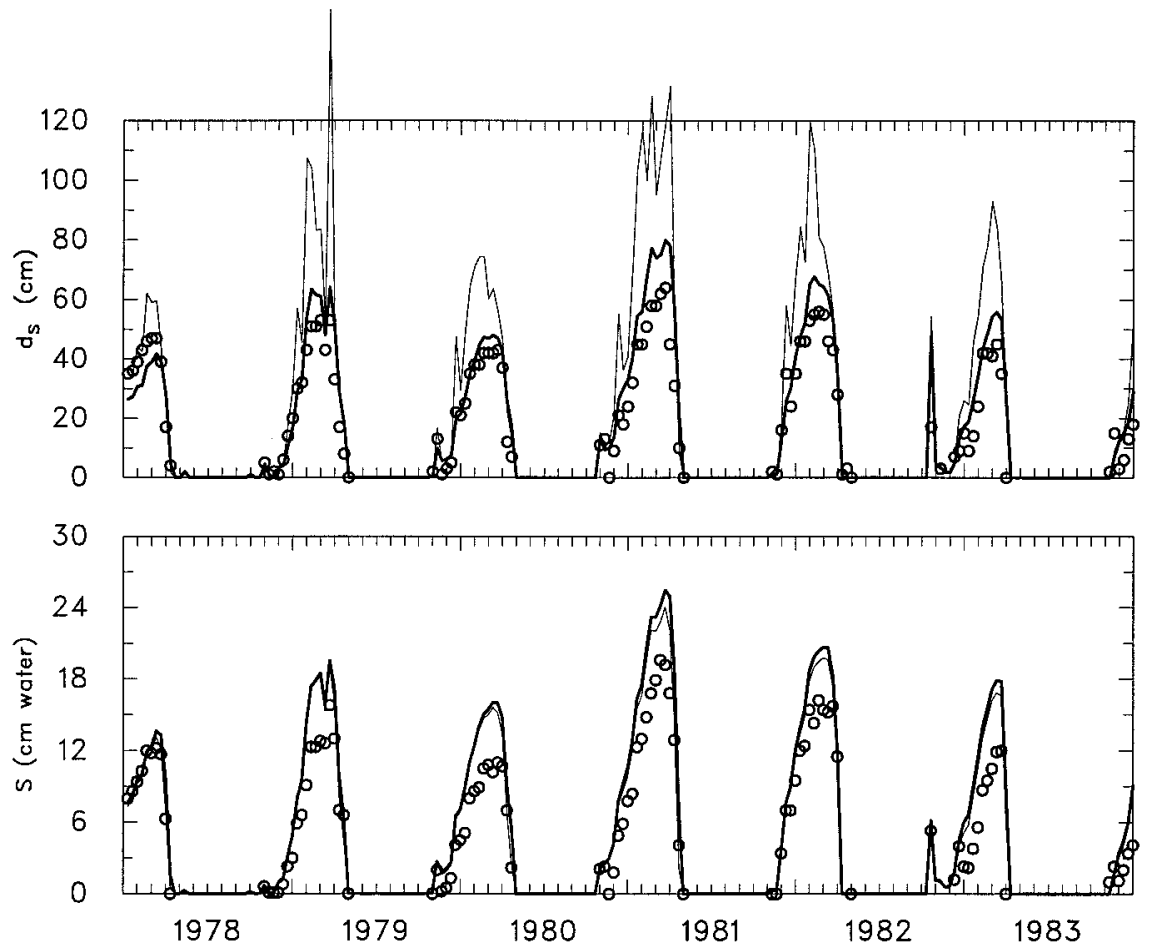

FIG. 12. Six-year time series of snow cover depth $(\mathrm{cm}$, top panel) and snow water equivalent (cm, second panel) for Kostroma. Circles are for measurements from snow courses, thin line for the original aging formula in snow density parameterization, and thick line for the modified aging formula with $\Delta P_{s}=60 \mathrm{~mm}$. The abscissa labels indicate the beginning of the months for the period 1978-83. 

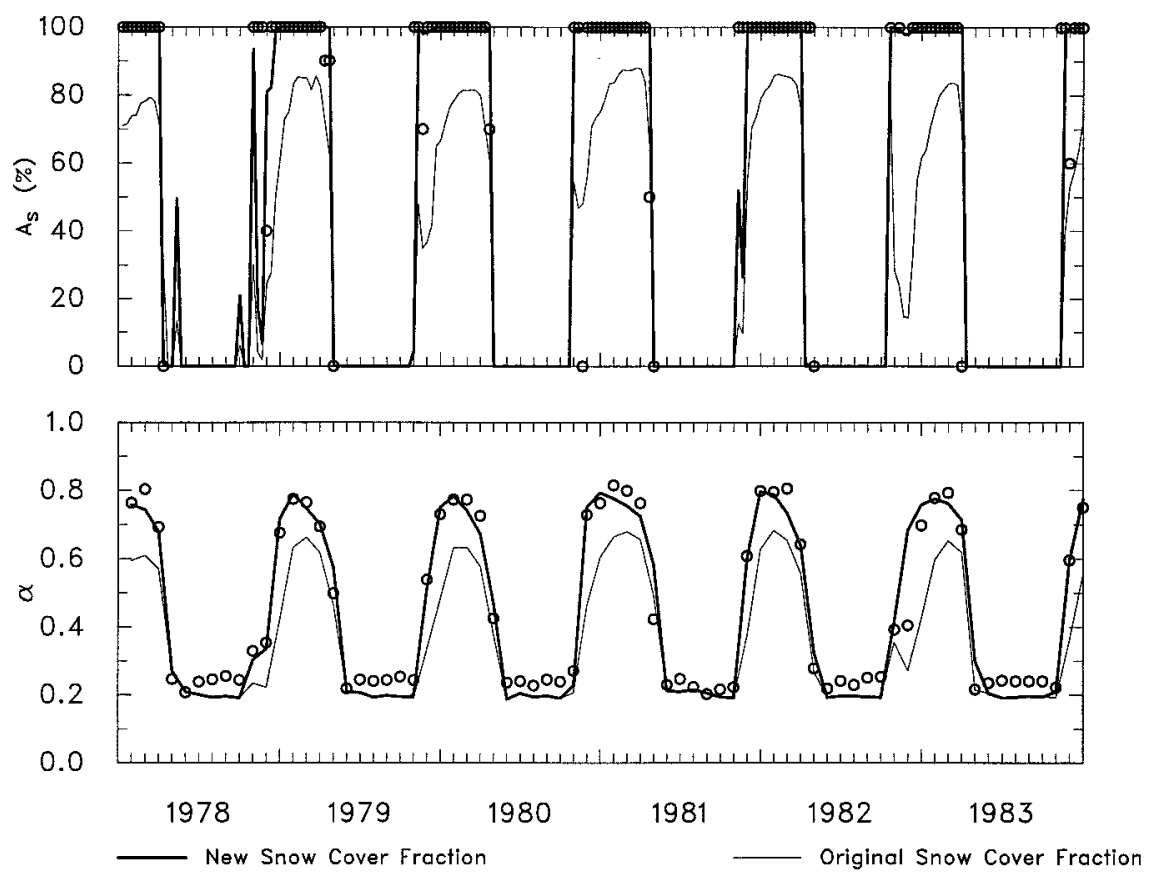

FIG. 14. Six-year time series of snow cover fraction (percent, top panel) and monthly energyweighted mean surface albedo (second panel) for Kostroma. Circles are for measurements, thin line for the original snow cover parameterization, and thick line for the modified method (32). The abscissa labels indicate the beginning of the months for the period 1978-83.

cation, site elevation, season (e.g., Auer 1974; Motoyama 1990) and the model used. Lynch-Stieglitz (1994) used $0^{\circ} \mathrm{C}$ in his multilayer snow model with a successful simulation. Other than use in a different study region and different parameterizations of snowmelt and sublimation, Lynch-Stieglitz's model differs from BATS in his inclusion of water storage and melting/refreezing within snowpack. It is found that without wind correction, the $2.2^{\circ} \mathrm{C}$ in BATS is appropriate for the dataset, but that with wind correction, $0^{\circ} \mathrm{C}$ leads to improved simulations.

Acknowledgments. Our gratitude extends to the scientists in the former USSR, without whose long-term effort in collecting the data this study would not have been possible. We thank C. A. Schlosser for making the data available for our use. Special thanks are due to Cas Sprout and Brian Auvine for editorial assistance in the preparation of the manuscript. Comments from three anonymous reviewers helped to improve the paper. This work was completed at the University of Arizona during tenure of a postdoctoral fellowship funded by NOAA Projects NA16RC0119-01 and NA56GP0184. This work is also partially funded by NOAA Grant NA36GP0311 and NASA EOS Interdisciplinary Scientific Research Program (UPN 429-81-22; UPN 42881-22). The views expressed herein are those of the authors and do not necessarily reflect the views of NOAA, NASA, or any of their subagencies.

\section{REFERENCES}

Aguado, E., 1985: Radiation balances of melting snow covers at an open site in the central Sierra Nevada, California. Water Resour. Res., 21, 1649-1654.

Anderson, E. A., 1976: A Point Energy and Mass Balance Model of a Snow Cover. Office of Hydrology, National Weather Service, $150 \mathrm{pp}$.

Auer, A. H., 1974: The rain versus snow threshold temperatures. Weatherwise, 27, 67.

Baker, D. G., R. H. Skaggs, and D. L. Ruschy, 1991: Snow depth required to mask the underlying surface J. Appl. Meteor., 30, 387-392.

Barker, H. W., Z. Li, and J.-P. Blanchet, 1994: Radiative characteristics of the Canadian Climate Centre second-generation general circulation model. J. Climate, 7, 1070-1091.

Barnett, T. P., L. Dumenil, U. Schlese, E. Roeckner, and M. Latif, 1989: The effect of Eurasian snow cover on regional and global climate variations. J. Atmos. Sci., 46, 661-685.

Barry, R. G., R. L. Armstrong, A. N. Krenke, and T. Kadomtseva, 1994: Cryospheric indices of global change. Final Report to National Science Foundation, National Snow and Ice Data Center, University of Colorado, Boulder, CO, $25 \mathrm{pp}$.

Clapp, R. B., and G. M. Hornberger, 1978: Empirical equations for some soil hydraulic properties. Water Resour. Res., 14, 601604.

Deardorff, J. W., 1978: Efficient prediction of ground surface temperature and moisture, with inclusion of a layer of vegetation. J. Geophys. Res., 83, 1889-1903.

Dickinson, R. E., 1984: Modelling evapotranspiration for three-dimensional global climate models. Climate Processes and Climate Sensitivity, Geophys. Monogr. No. 29, Maurice Ewing Vol. 5, Amer. Geophys. Union, 58-72.

, 1988: The force-restore model for surface temperatures and its generalizations. J. Climate, 1, 1086-1097. 
—, J. Jager, W. M. Washington, and R. Wolski, 1981: Boundary subroutine for the NCAR global climate model. NCAR Tech. Note NCAR/TN-173+IA, 75 pp.

—, A. Henderson-Sellers, P. J. Kennedy, and M. F. Wilson, 1986: Biosphere Atmosphere Transfer Scheme (BATS) for the NCAR Community Climate Model. NCAR Tech. Note NCAR/TN275+STR, 69 pp.

—, A. Henderson-Sellers, and P. J. Kennedy, 1993: Biosphere Atmosphere Transfer Scheme (BATS) Version le as coupled to the NCAR Community Climate Model. NCAR Tech. Note NCAR/ TN-387+STR, 72 pp.

Dingman, S. L., 1994: Physical Hydrology. Macmillan, 575 pp.

Douville, H., J.-F. Royer, and J.-F. Mahfouf, 1995a: A new snow parameterization for the Meteo-France climate model. Part I: Validation in stand-alone experiments. Climate Dyn., 12, 21-35.

,-- , and $-1995 \mathrm{~b}$ : A new snow parameterization for the Meteo-France climate model. Part II: Validation in a 3-D GCM experiment. Climate Dyn., 12, 37-52.

Drake, F., 1993: Global cloud cover and cloud water path from ISCCP C2 data. Int. J. Climatol., 13, 581-605.

Giorgi, F., M. R. Marinucci, and G. T. Bates, 1993a: Development of a second generation regional climate model (RegCM2). Part I: Boundary-layer and radiative transfer processes. Mon. Wea. Rev., 121, 2794-2813.

$\longrightarrow,-\longrightarrow$, and G. De Canio, 1993b: Development of a second generation regional climate model (RegCM2). Part II. Convective processes and assimilation of lateral boundary conditions. Mon. Wea. Rev., 121, 2814-2832.

Groisman, P. Ya., V. V. Koknaeva, T. A. Belokrylova, and T. R. Karl, 1991: Overcoming biases of precipitation measurement: A history of the USSR experience. Bull. Amer. Meteor. Soc., 72, $1725-1733$.

Hahmann, A. N., D. M. Ward, and R. E. Dickinson, 1995: Land surface temperature and radiative fluxes response of the NCAR CCM2/Biosphere-Atmosphere Transfer Scheme to modifications in the optical properties of clouds. J. Geophys. Res., 100, 23 239-23 252.

Henderson-Sellers, A., Z.-L. Yang, and R. E. Dickinson, 1993: The Project for Intercomparison of Land-Surface Parameterization Schemes. Bull. Amer. Meteor. Soc., 74, 1335-1349.

Idso, S. B., 1981: A set of equations for full spectrum and 8-14 $\mu \mathrm{m}$ and $10.5-12.5 \mu \mathrm{m}$ thermal radiation from cloudless skies. Water Resour. Res., 17, 295-304.

Jordan, R., 1991: A one-dimensional temperature model for a snow cover. U.S. Army Corps of Engineers, Cold Regions Research and Engineering Laboratory Special Rep. 91-16, 49 pp. [Available from NTIS, Springfield, VA 22161.]

Kimball, B. A., S. B. Idso, and J. K. Aase, 1982: A model of thermal radiation from partly cloudy and overcast skies. Water Resour. Res., 18, 931-936.

Loth, B., H.-F. Graf, and J. M. Oberhuber, 1993: Snow cover model for global climate simulations. J. Geophys. Res., 98, 10 45110464.

Lynch-Stieglitz, M., 1994: The development and validation of a simple snow model for the GISS GCM. J. Climate, 7, 1842-1855.

Matthews, E., 1983: Global vegetation and land use: New high-resolution data bases for climate studies. J. Climate Appl. Meteor., 22, 474-487.

Monteith, J. L., 1973: Principles of Environmental Physics. Edward Arnold, $241 \mathrm{pp}$

Motoyama, H., 1990: Simulation of seasonal snowcover based on air temperature and precipitation. J. Appl. Meteor., 29, 1104-1110.

Namias, J., 1985: Some empirical evidence for the influence of snow cover on temperature and precipitation. Mon. Wea. Rev., 113, 1542-1553.

Olson, J. S., J. A. Watts, and L. J. Allison, 1983: Carbon in live vegetation of major world ecosystems. U.S. Department of Energy DOE/NBB-0037, No. TR004, U.S. Department of Energy, Washington, DC, $152 \mathrm{pp}$.

Pinker, R. T., R. Frouin, and Z. Li, 1995: A review of satellite methods to derive surface shortwave irradiance. Remote Sens. Environ., 51, 108-124.

Pomeroy, J. W., D. M. Gray, and P. G. Landine, 1993: The prairie blowing snow model: Characteristics, validation, operation. $J$. Hydrol., 144, 165-192.

Razuvaev, V. N., E. B. Apasova, and R. A. Martuganov, 1995: Sixand three-hourly meteorological observations from 223 U.S.S.R. Stations. Tech. Memo. to the Oak Ridge National Laboratory, ORNL/CDIAC-66 NDP-048, 69 pp. [Available from ORNL, Oak Ridge, TN 37831-6335.]

Robock, A., K. Ya. Vinnikov, C. A. Schlosser, N. A. Speranskaya, and Y. Xue, 1995: Use of midlatitude soil moisture and meteorological observations to validate soil moisture simulations with biosphere and bucket models. J. Climate, 8, 15-35.

Satterlund, D. R., 1979: An improved equation for estimating longwave radiation from the atmosphere. Water Resour. Res., 15, 1649-1650.

Sellers, P. J., and J. L. Dorman, 1987: Testing the SiB using point micrometeorological and biophysical data. J. Climate Appl. Meteor., 26, 622-651.

—, Y. Mintz, Y. C. Sud, and A. Dalcher, 1986: A simple biosphere model ( $\mathrm{SiB}$ ) for use within general circulation models. J. Atmos. Sci., 43, 505-531.

- W. J. Shuttleworth, J. L. Dorman, A. Dalcher, and J. M. Roberts, 1989: Calibrating the Simple Biosphere Model for Amazonian tropical forest using field and remote sensing data. Part I: Average calibration with field data. J. Appl. Meteor., 28, 727-759.

Vinnikov, K. Ya., A. Robock, N. A. Speranskaya, and C. A. Schlosser, 1996: Scales of temporal and spatial variability of midlatitude soil moisture. J. Geophys. Res., 101, 7163-7174.

Walsh, J. E., W. H. Jasperson, and B. Ross, 1985: Influences of snow cover and soil moisture on monthly air temperature. Mon. Wea. Rev., 113, 756-768.

Wilson, M. F., and A. Henderson-Sellers, 1985: A global archive of land cover and soil data for use in general circulation climate models. J. Climatol., 5, 119-143.

,-- R. E. Dickinson, and P. J. Kennedy, 1987: Sensitivity of the Biosphere-Atmosphere Transfer Scheme (BATS) to the inclusion of variable soil characteristics. J. Climate Appl. Meteor., 26, 341-362.

Wiscombe, W. J., and S. G. Warren, 1980: A model for the spectral albedo of snow. I. Pure snow. J. Atmos. Sci., 37, 2712-2733.

Yang, D., B. E. Goodison, J. R. Metcalfe, V. S. Golubev, E. Elomaa, T. Gunther, R. Bates, T. Pangburn, C. L. Hanson, D. Emerson V. Copaciu, and J. Milkovic, 1995: Accuracy of Tretyakov precipitation gauge: Result of WMO intercomparison. Hydrol. Processes, 9, 877-895.

Yang, Z.-L., and R. E. Dickinson, 1996: Description of the BiosphereAtmosphere Transfer Scheme (BATS) for the Soil Moisture Workshop and evaluation of its performance. Global Planetary Change, 13, 117-134.

,-- , A. Henderson-Sellers, and A. J. Pitman, 1995: Preliminary study of spin-up processes in land surface models with the first stage data of Project for Intercomparison of Land Surface Parameterization Schemes Phase 1(a). J. Geophys. Res., 100, $16553-16578$.

Yeh, T.-C., R. T. Wetherald, and S. Manabe, 1983: A model study of the short-term climate and hydrologic effects of sudden snowcover removal. Mon. Wea. Rev., 111, 1013-1024. 